\title{
LOS VALORES PATRIMONIALES DE LA UNIDAD VECINAL SANTA MARINA EN EL CALLAO DESDE LA MIRADA DE SUS RESIDENTES Y VECINOS ${ }^{(*)}$
}

\author{
THE PATRIMONIAL VALUES OF SANTA MARINA'S NEIGHBORHOOD UNIT AT CALLAO \\ FROM THE LOOK OF ITS RESIDENTS AND NEIGHBORS \\ FIORELLA MECHATO LARA ${ }^{[\star]}$ \\ (D) https://orcid.org/0000-0003-2748-8627 \\ fmechatol@uni.pe \\ Grupo de investigación en patrimonio cultural Yuyai-UNI, Universidad Nacional de Ingeniería (Perú) \\ Fecha de recepción: 29 de octubre de 2019 \\ Fecha de aprobación: 28 de mayo de 2020
}

\section{RESUMEN}

La conservación del patrimonio es posible cuando sus actores trabajan en conjunto y en diálogo permanente; no se puede hablar de patrimonio si sus principales actores no saben reconocer el valor patrimonial del objeto. Por eso, fomentar la educación patrimonial en la población resulta clave para identificar las potencialidades de su conservación. Bajo un enfoque social, la investigación tiene como objetivo ubicar los valores patrimoniales, sobre la base de la clasificación de la Dra. Cristina Nieto Pérez (Universidad Politécnica de Valencia, España), en la Unidad Vecinal Santa Marina del Callao desde las opiniones y percepciones de sus actores directos: los residentes del lugar, los estudiantes, especialistas y expertos, e instituciones municipales. Mediante instrumentos como el uso de encuestas, entrevistas, sesiones en grupos de enfoque, y fichas de análisis se identificaron los valores patrimoniales, cuyos resultados revelaron diferencias en su reconocimiento según el contexto social pero una valoración más firme en una dimensión común.

\section{PALABRAS CLAVE}

Valores patrimoniales; Unidad Vecinal; Callao

\begin{abstract}
Heritage conservation is carried out when its heritage actors work together and dialogue; there is no heritage if its main actors do not recognize the heritage value of the object that is why promoting heritage education in them and identifying the potential of the object hand in hand with the population is the key to its conservation. Under a social approach, the research aims to track heritage values, based on the classification of Dr. Cristina Nieto (Polytechnic University of Valencia, Spain), in the Santa Marina Neighborhood Unit of Callao from the opinions and perceptions of its direct actors: local residents, students, specialists and experts, and municipal institutions. Through instruments like the use of surveys, interviews, focus group sessions, and analysis sheets, patrimonial values were identified and weighted, whose results of the study revealed a recognition of values differentiated by social context but strong in a common dimension.
\end{abstract}

\section{KEYWORDS}

Patrimonial values; Neighborhood Unit; Callao

\footnotetext{
(*) El presente artículo es una síntesis del trabajo de investigación de pregrado en 2019 titulado: Unidades vecinales del Callao como patrimonio edificado del movimiento moderno: análisis de los valores patrimoniales en el caso de la Unidad Vecinal Santa Marina. Dicha investigación se inició y desarrolló en la asignatura de Taller de Investigación en Historia 1 y 2 de la Facultad de Arquitectura, Urbanismo y Artes de la Universidad Nacional de Ingeniería bajo la responsabilidad del Dr. Arq. José Hayakawa Casas.

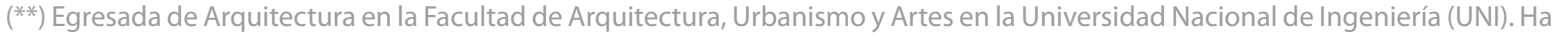
realizado prácticas pre-profesionales en la Oficina Unidad de Producción de Bienes y Servicios (UPBS) de la FAUA-UNI en el 2018. Formó parte del área de Talento Humano en el Proyecto Játi de la Universidad Nacional de Ingeniería (2017-2019). Actualmente integrante del Grupo de investigación en patrimonio cultural de la Yuyai-UNI de la Universidad Nacional de Ingeniería.
} 
devenir Vol. 7, Nº14, JULIO - DICIEMBRE 2020, PP. 11-34 - EstudIOS I ISSN 2312-7562 | E-ISSN 2616-4949

UNIVERSIDAD NACIONAL DE INGEENIERÍA, LIMA

doi: https://doi.org/10.21754/devenir.v7i14.761

Solo en el Centro Histórico del Callao, se reconocen 70 monumentos como Patrimonio Cultural de la Nación, y hay 154 bienes de valor monumental registrados en el Inventario del Patrimonio Monumental Inmueble del Centro Histórico del Callao (Soria, 1994). Sin embargo, más allá del Centro Histórico del Callao, el cual ha tenido una serie de intervenciones en los últimos años, encontramos inmuebles característicos del Callao, diferentes a los ya conocidos de su etapa virreinal y republicana. Uno de ellos, de los más grandes en extensión, y objeto de la presente investigación, es la Unidad Vecinal Santa Marina, conjunto arquitectónico de vanguardia propio de los años cincuenta que formó parte del proyecto para la reconstrucción del Callao (Montestruque y Fabbri, 2017). Santa Marina, es una de las primeras obras modernas de residencia colectiva en la ciudad portuaria que alberga a cientos de chalacos. Después de haber sido un barrio que se caracterizaba por su fraternidad vecinal, hoy en día sus propios residentes y los medios de comunicación lo consideran una "zona peligrosa" debido a los diversos casos de delincuencia registrados en la última década (Univisión, 2016; RPP, 2015).

Al observar las calles descuidadas, la falta de iluminación, la carencia de actividades vecinales en sus espacios públicos, se evidencia una situación de crisis, de debilitamiento y degradación de los valores patrimoniales de este conjunto vecinal.

Desde esta premisa, el objetivo de la investigación es el reconocer e identificar los valores patrimoniales que aún tiene la Unidad Vecinal Santa Marina, y su ponderación entre los vecinos. El reconocimiento de estos valores patrimoniales será analizado de acuerdo con los actores patrimoniales: residentes y vecinos cercanos, especialistas, representantes institucionales, para así tener una visión holística del objeto patrimonial.

\section{Metodología: La investigación Acción Participativa, el análisis bajo la mirada social}

El estudio explorativo de enfoque mixto, se realizará con una metodología de diseño fenomenológico y de ejecución concurrente (Hernandez, 2010, pp. 115-116) y en base a la Investigación Acción Participativa (IAP) que relaciona el conocimiento con la acción social (Salazar, 2006).

Los objetivos que esta tipología de investigación persigue el empoderamiento de la población, mejorar su calidad de vida y fomentar el desarrollo desde la propia comunidad. Entiende la investigación aplicada como una investigación de acción, en la que el investigador participa activamente en el proceso y actúa como un agente regulador o mediador, no como un observador externo de la comunidad que pretende describir o analizar. (Nieto, 2018, pp. 146-147)

Se realizó la identificación de actores patrimoniales en relación con el bien y técnicas e instrumentos correspondientes que permitan identificar los valores patrimoniales según la clasificación de Nieto (2018) (ver Tabla 1).

En cuanto a la elaboración del instrumento de investigación, se formularon las preguntas con el objetivo de identificar estimaciones de valor según el posicionamiento del sujeto respecto al objeto. Siguiendo el proceso de lectura, transcripción e interpretación de respuestas mediante una ficha de análisis (ver Figura 1) que permita identificar los valores patrimoniales en sus estimaciones, así como el factor, elemento o caso que permite la estimación. Esto será contabilizado y comparado al total de participantes para comprender la preponderancia y nivel de reconocimiento entre los valores identificados (ver Tabla 2).

Para las encuestas físicas, se eligieron personas mayores de 14 años y transeúntes de la zona que visiten constantemente el lugar (como clientes de la posta médica, padres de familia de los colegios, trabajadores de la zona). Todas las encuestas físicas se desarrollaron entre las 9am y $5 \mathrm{pm}$, en los espacios públicos de la Unidad Vecinal. 
Tabla 1. Tabla de actores y técnicas de investigación.

\begin{tabular}{|c|c|c|c|c|c|}
\hline \multicolumn{3}{|c|}{ Actores } & \multirow{2}{*}{$\begin{array}{c}\text { Nivel de } \\
\text { implicación }\end{array}$} & \multirow{2}{*}{ Técnica } & \multirow{2}{*}{ Objetivo y método } \\
\hline Universo & Unidad muestral & Unidad informante & & & \\
\hline \multirow[t]{8}{*}{ Población } & \multirow{2}{*}{$\begin{array}{l}\text { Residentes de Santa } \\
\text { Marina }\end{array}$} & Vecinos adultos de zona norte & Alta & \multirow[t]{3}{*}{ Encuesta } & \multirow{3}{*}{$\begin{array}{l}\text { Identificar los valores patrimoniales } \\
\text { percibidos desde diferentes pers- } \\
\text { pectivas respecto al objeto. }\end{array}$} \\
\hline & & Vecinos adultos de zona sur & Alta & & \\
\hline & Vecinos cercanos & Vecinos adultos de alrededores & Media & & \\
\hline & \multirow[t]{3}{*}{$\begin{array}{l}\text { Público online } \\
\text { (Usuarios Face- } \\
\text { book) }\end{array}$} & $\begin{array}{l}\text { Seguidores de página } \\
\text { "De chalacos es" }\end{array}$ & Media & \multirow[t]{3}{*}{$\begin{array}{l}\text { Análisis de } \\
\text { fichas }\end{array}$} & \multirow{3}{*}{$\begin{array}{l}\text { Identificar los valores patrimoniales } \\
\text { en base al análisis de comentarios y } \\
\text { reacciones en publicaciones online } \\
\text { populares. }\end{array}$} \\
\hline & & $\begin{array}{l}\text { Seguidores de página } \\
\text { "El Callao que se nos fue" }\end{array}$ & Media & & \\
\hline & & $\begin{array}{l}\text { Seguidores de página } \\
\text { "Santa Marina Norte" }\end{array}$ & Media & & \\
\hline & \multirow[t]{2}{*}{$\begin{array}{l}\text { Niños y adolescen- } \\
\text { tes que frecuentan } \\
\text { Santa Marina }\end{array}$} & $\begin{array}{l}\text { Alumnos de primaria del } \\
\text { Colegio Junior Cesar de los Ríos }\end{array}$ & Media & $\begin{array}{l}\text { Dinámica } \\
\text { individual }\end{array}$ & $\begin{array}{l}\text { Identificar los elementos caracte- } \\
\text { rísticos de Santa Marina a través de } \\
\text { sus imaginarios urbanos }\end{array}$ \\
\hline & & $\begin{array}{l}\text { Alumnos de secundaria del } \\
\text { Colegio Junior Cesar de los Ríos }\end{array}$ & Media & $\begin{array}{l}\text { Dinámica } \\
\text { grupal }\end{array}$ & $\begin{array}{l}\text { Identificar en base a debate y diá- } \\
\text { logo, los valores formales, de uso y } \\
\text { simbólicos, del lugar. }\end{array}$ \\
\hline \multirow[t]{3}{*}{$\begin{array}{l}\text { Especialistas/ } \\
\text { Expertos }\end{array}$} & $\begin{array}{l}\text { En el Movimiento } \\
\text { Moderno como } \\
\text { Patrimonio }\end{array}$ & Arq. Manuel Baca & Baja & \multirow{4}{*}{$\begin{array}{l}\text { Entrevista } \\
\text { semi-estructu- } \\
\text { rada }\end{array}$} & \multirow{4}{*}{$\begin{array}{l}\text { Identificar los valores patrimoniales } \\
\text { a partir de las opiniones y conoci- } \\
\text { mientos de los expertos. Compren- } \\
\text { der el contexto histórico e institu- } \\
\text { cional en el cual se encuentra Santa } \\
\text { Marina como bien patrimonial. }\end{array}$} \\
\hline & $\begin{array}{l}\text { En Historia del Mo- } \\
\text { vimiento Moderno }\end{array}$ & Arq. José Beingolea & Baja & & \\
\hline & $\begin{array}{l}\text { Involucrados en la } \\
\text { proyección de la } \\
\text { UVSM }\end{array}$ & Adolfo Córdova & Baja & & \\
\hline Institución & $\begin{array}{l}\text { Dirección Descon- } \\
\text { centrada de Cultura } \\
\text { del Callao }\end{array}$ & Arq. Frank Bonifaz & Baja & & \\
\hline
\end{tabular}

Para las encuestas virtuales se obtuvo el apoyo de las páginas de Facebook: "De Chalacos es", "El Callao que se nos fue", "Publicaciones Comerciales en el Antiguo Callao", "Antiguas Crónicas" del Callao". Orientadas a fomentar la cultura chalaca compartieron la encuesta y se obtuvo un mayor alcance.

Para las sesiones de grupo en los colegios se escogió un área de primaria y otro de secundaria del Colegio Junior Cesar de los Ríos, de acuerdo con la disponibilidad de sus horarios de clase.

Se encuestó en total a 121 personas ente encuestas físicas y virtuales. De las cuales el 36\% son residentes de Santa Marina Norte, el 31\% de Santa Marina Sur y el otro 31\% población flotante (vecinos cercanos y trabajadores). En las sesiones de grupo participaron 30 alumnos de quinto año de primaria y 24 del primer año de secundaria. 
devenir Vol. 7, N¹4, JULIO - DICIEMBRE 2020, PP. 11-34 - EstudIOS I ISSN 2312-7562 | E-ISSN 2616-4949

UNIVERSIDAD NACIONAL DE INGEEIERÍA, LIMA

doi: https://doi.org/10.21754/devenir.v7i14.761

\begin{tabular}{|c|c|c|c|}
\hline Problema & Objetivo & Categorías & $\begin{array}{c}\text { Preguntas aplicadas en la } \\
\text { encuesta }\end{array}$ \\
\hline \multirow[t]{4}{*}{$\begin{array}{l}\text { ¿Cuáles son los valores patrimo- } \\
\text { niales que caracterizan a la Unidad } \\
\text { Vecinal Santa Marina, según sus } \\
\text { actores directos (residentes y ve- } \\
\text { cinos)? }\end{array}$} & $\begin{array}{l}\text { Identificar los valores patrimonia- } \\
\text { les de Santa Marina según las per- } \\
\text { cepciones de los sujetos, analizan- } \\
\text { do el objeto desde fuera. }\end{array}$ & $\begin{array}{l}\text { Valores patrimoniales como ob- } \\
\text { servador externo: Importancia y } \\
\text { reconocimiento del objeto }\end{array}$ & $\begin{array}{l}\text { ¿Qué es lo más característico que } \\
\text { tiene Santa Marina que te resulte } \\
\text { agradable? ¿Con qué lo identifica- } \\
\text { rías? }\end{array}$ \\
\hline & $\begin{array}{l}\text { Identificar los valores patrimonia- } \\
\text { les de según las percepciones de } \\
\text { los sujetos, analizando el objeto } \\
\text { donde ellos son parte y existe un } \\
\text { vínculo de afecto. }\end{array}$ & $\begin{array}{l}\text { Valores patrimoniales como ob- } \\
\text { servador interno: Importancia } \\
\text { personal }\end{array}$ & $\begin{array}{l}\text { De todos los años pasados aquí, } \\
\text { ¿Qué no cambiarías de Santa Mari- } \\
\text { na? ¿Qué lo hace importante para } \\
\text { ti? }\end{array}$ \\
\hline & $\begin{array}{l}\text { Identificar si el objeto patrimonial } \\
\text { se encuentra en uso y mediante } \\
\text { qué tipo de actividades. }\end{array}$ & Dinámicas del uso del bien & $\begin{array}{l}\text { ¿Cuáles de esas distintas activida- } \\
\text { des observas que se pueden rea- } \\
\text { lizar en el barrio de Santa Marina? }\end{array}$ \\
\hline & $\begin{array}{l}\text { Estimar el grado de satisfacción } \\
\text { que tienen los residentes de Santa } \\
\text { Marina al vivir allí. }\end{array}$ & $\begin{array}{l}\text { Grado de satisfacción de vivir en } \\
\text { Santa Marina }\end{array}$ & $\begin{array}{l}\text { ¿En la escala del } 1 \text { al } 5 \text { que tanto } \\
\text { disfrutas Santa Marina? ( } 1=\text { muy } \\
\text { poco, } 5=\text { bastante) }\end{array}$ \\
\hline
\end{tabular}

Elaboración propia, 2019.

\begin{tabular}{|l|l|l|l|}
\hline EDAD: & \multicolumn{3}{|c|}{ Tema y pregunta } \\
\cline { 3 - 5 } Años en la U.V.: & $\begin{array}{l}\text { Importancia de } \\
\text { reconocimiento de valor: } \\
\text { ¿Qué es lo más característico } \\
\text { que tiene Santa Marina? ¿Con } \\
\text { qué lo identificas? }\end{array}$ & $\begin{array}{l}\text { Dinámicas de uso: } \\
\text { iCuáles son las distintas } \\
\text { actividades que observas } \\
\text { que se pueden realizar en el } \\
\text { barrio de Santa Marina? }\end{array}$ & $\begin{array}{l}\text { Importancia personal como } \\
\text { objeto de valor: } \\
\text { iQué hace Santa Marina } \\
\text { importante para ti? ¿Qué no } \\
\text { cambiarías? }\end{array}$ \\
\hline $\begin{array}{llll}\text { Zona de } \\
\text { procedencia: }\end{array}$ & & & \\
\hline Respuesta & & & \\
\hline $\begin{array}{l}\text { Casos o factores que } \\
\text { causan la estimación }\end{array}$ & & & \\
\hline Valor(es) Formal(es) & & & \\
\hline Valor(es) de Uso & & & \\
\hline Valor(es) Simbólico(s) & & & \\
\hline Grado de Satisfacción & & & \\
\hline
\end{tabular}

Figura 1. Modelo de ficha de análisis de encuesta. Elaboración propia, 2019.

\section{Marco referencial}

El marco referencial de la presente investigación se desarrolla en torno a 4 tópicos que envuelven el objeto de estudio: La ciudad del Callao, las Unidades Vecinales, la arquitectura del Movimiento Moderno y la teoría de valoración patrimonial.

\section{La teoría patrimonial}

Concepto. Ballart define el valor de un bien como "...aprecio hacia determinados objetos por el mérito que atesoran, por la utilidad que manifiestan, o por su aptitud para satisfacer necesidades o proporcionar bienestar" (Hayakawa, 2012, p. 2). 


\begin{tabular}{|c|c|c|}
\hline Grupo & Valores & Descripción \\
\hline \multirow[t]{5}{*}{ Formal } & Artístico & Por la calidad técnico-artística del bien \\
\hline & Estético & $\begin{array}{l}\text { Presenta armonía o belleza, por la suma de añadidos o mo- } \\
\text { dificaciones sufridas que le dan un aspecto singular }\end{array}$ \\
\hline & Novedad & Supuso un hito singular en su origen \\
\hline & Originalidad & $\begin{array}{l}\text { Sus cualidades son significativas en relación a obras del } \\
\text { mismo autor, tipo, periodo o región. }\end{array}$ \\
\hline & $\begin{array}{l}\text { Conjunto o indivisi- } \\
\text { bilidad }\end{array}$ & $\begin{array}{l}\text { Se trata de bien formado de partes indivisibles y que única- } \\
\text { mente relacionadas tienen sentido patrimonial. }\end{array}$ \\
\hline \multirow[t]{6}{*}{ De uso } & Uso & $\begin{array}{l}\text { Está en uso, bien sea por la función para la que fue creado, } \\
\text { o por un uso alternativo fruto de las necesidades contem- } \\
\text { poráneas. }\end{array}$ \\
\hline & Investigación & Contribuye al incremento del conocimiento. \\
\hline & Educativo & Contribuye a transmitir o canalizar el conocimiento. \\
\hline & $\begin{array}{l}\text { Sentimental o per- } \\
\text { sonal }\end{array}$ & Fomenta las relaciones interpersonales \\
\hline & Social o identitario & $\begin{array}{l}\text { Es un elemento de nexo social. Promueve la identificación } \\
\text { cultural de un grupo. }\end{array}$ \\
\hline & Económico & $\begin{array}{l}\text { Se le puede asociar una cantidad económica. También su } \\
\text { uso y puesta en marcha genera rendimiento económico. }\end{array}$ \\
\hline \multirow[t]{4}{*}{ Simbólico } & $\begin{array}{l}\text { Histórico o testimo- } \\
\text { nial }\end{array}$ & $\begin{array}{l}\text { Es un documento de la Historia, testifica formas de vida o } \\
\text { momentos históricos. }\end{array}$ \\
\hline & Antigüedad & Su aspecto antiguo produce nostalgia y belleza. \\
\hline & Asociativo & $\begin{array}{l}\text { El bien se puede asociar a una persona famosa o significa- } \\
\text { tiva. }\end{array}$ \\
\hline & $\begin{array}{l}\text { Conmemorativo o } \\
\text { monumental }\end{array}$ & Rememora personas o eventos significativos. \\
\hline
\end{tabular}

La valoración del patrimonio es expresada de diversas formas y existen investigaciones para clasificarlas. La presente investigación se basa en la clasificación de Nieto (2018), que define el patrimonio como aquella construcción social a la que se le atribuyen valores y elabora una síntesis basada en las clasificaciones de Appelbaum (2007) y Montañez (2016) logrando identificar 15 valores (ver Tabla 3).

\section{El Movimiento Moderno como patrimonio}

\section{En el Mundo}

En 1998, con la creación del DOCOMOMO, empieza un proceso de fichaje, para las diversas edificaciones del movimiento moderno (Díaz, 2009, pp. 222). El DOCOMOMO Internacional, organización sin fines de lucro, define un modelo de ficha, el cual es adaptado e interpretado en los diversos países donde se realiza tanto el fichaje como la documentación de los edificios de este movimiento. En esta ficha se definen los valores arquitectónicos del bien según criterios de análisis explicados en la Tabla 4.

Para abordar la investigación desde un enfoque arquitectónico y urbanístico se interpreta la clasificación de valores patrimoniales de Nieto en adición a los criterios de valor propuestos por el Docomomo internacional y será esta interpretación la que servirá como base para discernir entre las estimaciones de valor referentes a la Unidad Vecinal Santa Marina (ver Tabla 5). 
devenir Vol. 7, N¹4, JULIO - DICIEMBRE 2020, PP. 11-34 - Estudios I ISSN 2312-7562 | E-ISSN 2616-4949

UNIVERSIDAD NACIONAL DE INGENIERÍA, LIMA

doi: https://doi.org/10.21754/devenir.v7i14.761

Tabla 4. Criterios de valor de bienes arquitectónicos del Movimiento Moderno según Docomomo Internacional.

\section{Criterios de valor Docomomo Internacional}

\begin{tabular}{lll}
\hline Valor inrinseco & Apreciación técnica & $\begin{array}{l}\text { Uso de nuevos materiales y nuevas técnicas. Se deben considerar los materiales de construcción y } \\
\text { los acabados, la estructura y los servicios y, si corresponde, los métodos de construcción. }\end{array}$ \\
& Apreciación social & $\begin{array}{l}\text { Considere aquíl los propósitos y efectos sociales. Si el proyecto resultó como exigencia de un nue- } \\
\text { vo tipo de edificio en su tiemo, o sirvió a una estrategia social o económica más amplia como las } \\
\text { nuevas ciudades. } \\
\text { Aquí se consideran las estrategias formales del diseñador y las cualidades formales del edificio. }\end{array}$ \\
$\begin{array}{l}\text { Significado } \\
\text { comparativo }\end{array}$ & Estado canónico & $\begin{array}{l}\text { Esta pregunta se refiere a la apreciación arquitectónica, la recepción en la prensa especializada, } \\
\text { así como el impacto del proyecto en la práctica del diseño, a nivel internacional o local. }\end{array}$ \\
& Valor de referencia & $\begin{array}{l}\text { Considere aquí el contexto histórico. Se puede establecer relaciones entre el edificio o el sitio } \\
\text { considerado. }\end{array}$ \\
\hline
\end{tabular}

Elaboración propia sobre la base de Docomomo Internacional (2004).

Tabla 5. Interpretación de valores patrimoniales aplicado a los bienes arquitectónicos del Movimiento Moderno.

\begin{tabular}{|c|c|c|c|c|}
\hline \multicolumn{2}{|c|}{$\begin{array}{l}\text { Valores patrimoniales } \\
\text { (Nieto, 2018) }\end{array}$} & \multicolumn{2}{|c|}{$\begin{array}{l}\text { Criterios de valor para la ficha } \\
\text { Docomomo Internacional }\end{array}$} & \multirow{2}{*}{$\begin{array}{l}\text { Descripción } \\
\text { Por la calidad técnica y artística, tanto en su infraestructura como en } \\
\text { su configuración urbana. Esta relacionada al uso de nuevos materia- } \\
\text { les, técnicas de construcción, acabados o estructuras. }\end{array}$} \\
\hline Formal & Artístico & $\begin{array}{l}\text { Enfoque urbano } \\
\text { - arquitectónico }\end{array}$ & $\begin{array}{l}\text { Apreciación } \\
\text { técnica }\end{array}$ & \\
\hline & Estético & & $\begin{array}{l}\text { Apreciación } \\
\text { estética }\end{array}$ & $\begin{array}{l}\text { Por su cualidad estética, el bien arquitectónico o parte de él resulta } \\
\text { bello o armonioso a la vista, puede producir tranquilidad y/o comodi- } \\
\text { dad. Está relacionado a elementos visuales. }\end{array}$ \\
\hline & Novedad & & - & Por ser un hito visual y singular respecto a su entorno urbano. \\
\hline & Originalidad & & $\begin{array}{l}\text { Valor de refe- } \\
\text { rencia }\end{array}$ & $\begin{array}{l}\text { Por ser referencia respecto a otras obras arquitectónicas del mismo } \\
\text { autor, tipología o región. }\end{array}$ \\
\hline & $\begin{array}{l}\text { Conjunto o indivisi- } \\
\text { bilidad }\end{array}$ & & - & $\begin{array}{l}\text { Por su cualidad urbana de unidad, el bien se entiende como un con- } \\
\text { junto formado por partes indivisibles. }\end{array}$ \\
\hline \multirow[t]{6}{*}{ De uso } & Uso & \multirow{6}{*}{\multicolumn{2}{|c|}{ Apreciación social }} & $\begin{array}{l}\text { EL bien arquitectónico está en uso, ya sea para sus funciones } \\
\text { originales o para usos alternativos que responden a las necesidades } \\
\text { contemporáneas. }\end{array}$ \\
\hline & Investigación & & & Su estudio permite incrementos de conocimiento humano. \\
\hline & Educativo & & & Sus instalaciones permiten canalizar o transmitir conocimiento. \\
\hline & $\begin{array}{l}\text { Sentimental o } \\
\text { personal }\end{array}$ & & & $\begin{array}{l}\text { Fomenta la formación de relaciones sociales establecidas por sus } \\
\text { habitantes. }\end{array}$ \\
\hline & Social o identitario & & & $\begin{array}{l}\text { Genera identidad cultural y sentido de pertenencia. El proyecto sirvió } \\
\text { a una estrategia social mas amplia (a nivel local, o nacional) }\end{array}$ \\
\hline & Económico & & & $\begin{array}{l}\text { Genera beneficios económicos para sus usuarios o trabajadores. El } \\
\text { proyecto sirvió a una estrategia económica más amplia }\end{array}$ \\
\hline \multirow[t]{4}{*}{ Simbólico } & $\begin{array}{l}\text { Histórico o testi- } \\
\text { monial }\end{array}$ & \multicolumn{2}{|c|}{$\begin{array}{l}\text { Estado canónico (cuestión de } \\
\text { modelo) }\end{array}$} & $\begin{array}{l}\text { Contribuye a conocer un momento de la Historia, genera conciencia } \\
\text { sobre el tiempo en que fue edificado. }\end{array}$ \\
\hline & Antigüedad & \multicolumn{2}{|l|}{-} & Genera nostalgia debido a su aspecto antiguo. \\
\hline & Asociativo & \multicolumn{2}{|l|}{-} & $\begin{array}{l}\text { Genera nostalgia y aprecio debido a la asociación con una persona } \\
\text { significativa. }\end{array}$ \\
\hline & $\begin{array}{l}\text { Conmemorativo o } \\
\text { monumental }\end{array}$ & \multicolumn{2}{|l|}{-} & $\begin{array}{l}\text { Genera nostalgia y aprecio debido a la asociación con un evento } \\
\text { pasado significativo. }\end{array}$ \\
\hline
\end{tabular}

Elaboración propia sobre la base de Docomomo Internacional (2004) y Nieto (2018). 


\section{En el Perú}

Acevedo y Llona mediante la creación del CAMM (Catálogo del Movimiento Moderno en el Perú) dan el primer paso para la documentación de diversos proyectos de este periodo en el Perú. En conjunto y con el apoyo del Ministerio de Cultura, buscan poner en valor este tipo de arquitectura, comenzando por el reconocimiento local y de las autoridades. Así también se invita e incita a generar más investigación que involucre este periodo para seguir el camino que ya han trazado (Acevedo y Llona, 2016, p. 19).

\section{El Movimiento Moderno y la Unidad Vecinal}

\section{El Movimiento Moderno en el Perú, la crisis de vivienda y el origen de la Unidad Vecinal}

Para Alejandra Acevedo y Michelle Llona, el Movimiento Moderno tuvo mayor producción arquitectónica en la década de los 50, entre 1945 y 1965. Entendemos como el punto de partida del Movimiento Moderno en el Perú, los sucesos en el cambio de enseñanza de arquitectura en el Perú:

Los cambios empiezan en 1945, en la Universidad Nacional de Ingeniería (UNI) cuando el Centro de Estudiantes de Arquitectura (CEA) promueve una reforma del Plan de Estudios con lo cual se logra un año después, la creación del Departamento de Arquitectura y el inicio del proceso de modernización de la enseñanza. Este deseo de cambio y renovación dentro del CEA fue motivado por un libro del arquitecto Luis Miró Quesada: Espacio en el tiempo, primer volumen peruano que aborda la nueva arquitectura como consecuencia de un cambio estructural en la sociedad. Posteriormente, en 1947, el grupo del CEA, bajo la tutela de Miró Quesada forma la Agrupación Espacio, que reunió a arquitectos, intelectuales y artistas. y publicó un manifiesto en el que se plantean las ideas fundamentales sobre las que se basa este periodo. $(2016$, p.19)

Otro tema relevante de este movimiento, es la vivienda colectiva. Para Elio Martuccelli, la necesidad de vivienda ocasionada por la migración del campo a la ciudad que se producía en la capital generó una preocupación en los arquitectos de la época, y es mediante las ideas traídas de Europa que se propone como solución proyectos como las unidades vecinales y los conjuntos de viviendas para obreros.

Ser arquitecto moderno en Europa durante la década de 1920 era dedicarse a la vivienda social. Ejemplos notables de esos años encontramos en Alemania y Holanda, así como en Inglaterra y Francia, donde se desarrollaron al respecto obras importantes. Esa preocupación se extendió rápidamente a otros países europeos y luego llegó a otros lugares del mundo, incluyendo el Perú. (2016, p. 37)

En el Perú, estas unidades vecinales comenzaron a instaurarse en los planes de vivienda para Lima, en la segunda mitad del siglo XX. La instauración de estas unidades vecinales generó debate entre los arquitectos de la época, aun así, se resaltaba su potencial como espacio urbano.

Es cierto que todas estas propuestas de vivienda colectiva estatal no resolvieron el enorme déficit habitacional en la ciudad y que estuvieron destinadas, casi todas, a la clase media limeña. Pero también es cierto que, luego de varias décadas, uno siente que el balance en términos de espacio urbano es más que positivo (Martuccelli, 2016, p. 40).

\section{Entonces, ¿cómo se define una Unidad Vecinal?}

Sert realiza una definición de la Unidad Vecinal, basándose en los casos tanto europeos como en los planes a realizarse en Latinoamérica.

Sert define la Unidad Vecinal como una célula en la estructura de una ciudad. Una unidad física y social inserta en una comunidad mayor, cuyo tamaño no es tan grande como para que sus residentes pierdan su identidad, pero suficientemente pequeña para que la expresión de 
devenir Vol. 7, N¹4, JULIO - DICIEMBRE 2020, PP. 11-34 - Estudios I ISSN 2312-7562 | E-ISSN 2616-4949

UNIVERSIDAD NACIONAL DE INGGENIERÍA, LIMA

doi: https://doi.org/10.21754/devenir.v7i14.761

COMUNIDAD MAYOR (EXISTENTE O EN DESARROLLO)

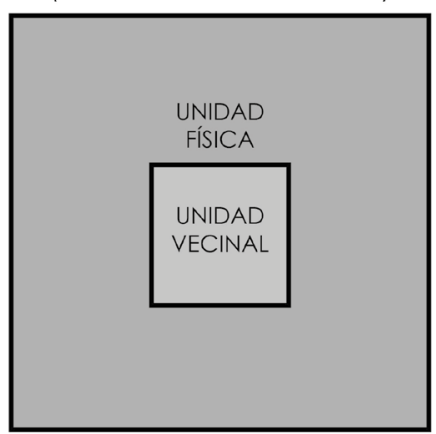

Figura 2. Esquema de conformación de una Unidad Vecinal. Elaboración propia sobre la base de Ruiz, M. (2003), Tarchópulos, D. (2014).

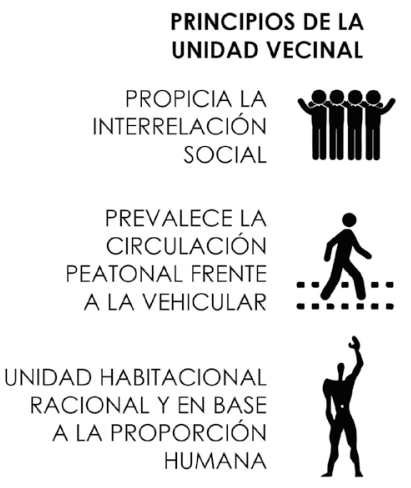

UNIDAD VECINAL comprende:

Terreno*

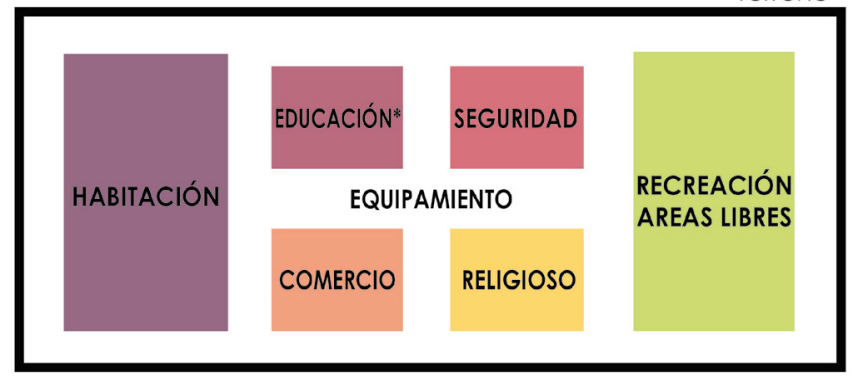

* El centro educativo es el elemento influyente en el tamaño/capacidad Capacidad máxima: 5000 hab. su conciencia cívica sea efectiva. Su tamaño debe permitir que los residentes sean vecinos y acomodar una población diversa que pueda ser cubierta por los servicios de las instalaciones sociales, recreacionales, religiosas y educacionales que son esenciales para su bienestar (Tarchópulos, 2014).

Tras el análisis de Mawi Ruiz, respecto a las diversas unidades vecinales que se desarrollaron en Lima, entendemos como la definición de Unidad Vecinal (tal como se llevó a cabo en el contexto peruano) como:

... la célula urbana o barrio que cuenta con el equipamiento necesario para desarrollarse de manera autosuficiente y resuelve los problemas de habitación, educación, seguridad, recreación y comercio de sus habitantes.

El terreno, los centros educativos y el comercio son elementos que influyen directamente en el tamaño y la capacidad de las unidades vecinales, estimándose 5000 habitantes como la capacidad máxima de estas unidades, para que cumplan de manera eficiente todas las necesidades que estos pobladores pudieran tener. (Ruiz, 2003)

Finalmente, podemos sintetizar esquemáticamente lo que significa la confirmación de una Unidad Vecinal en esta investigación en base a las fuentes citadas, así como los equipamientos y principios debe seguir para ser considerada una (ver Figura 2).

\section{Unidad Vecinal Santa Marina}

\section{Santa Marina en el tiempo}

Durante el siglo XX, en el Perú se materializaron ideas que buscaron solucionar la necesidad de vivienda y la descentralización del centro de Lima, entre ellas estuvo la implantación de Unidades Vecinales. Kahatt refiere, que uno de los intelectuales que trajo la idea de la unidad vecinal al Perú, fue Luis Dórich, creador del Instituto de Urbanismo en 1944 con Fernando Belaúnde, Carlos Morales y Luis Ortiz de Zevallos. "Dorich conocía las ideas de Greenbelt Towns tanto como las del Neighborhood Unit, no solo por sus estudios del MIT, sino porque su profesor Thomas Adams fue un gran defensor y promotor de la idea de Perry (Kahatt, 2015)".

El término y el proyecto como tal de Unidad Vecinal, aparece y se emplea en el Plan de Vivienda del gobierno peruano en 1945, como la solución al problema de vivienda que afectaba el país. Apostaba por la descentralización de una manera ordenada a través de diferentes proyectos de Unidades Vecinales en Lima y Callao. Entre las más destacadas y estudiadas está la Unidad Vecinal No3 (UV3) y la Unidad Vecinal Matute (Kahatt, 2015) (ver Figura 3). 

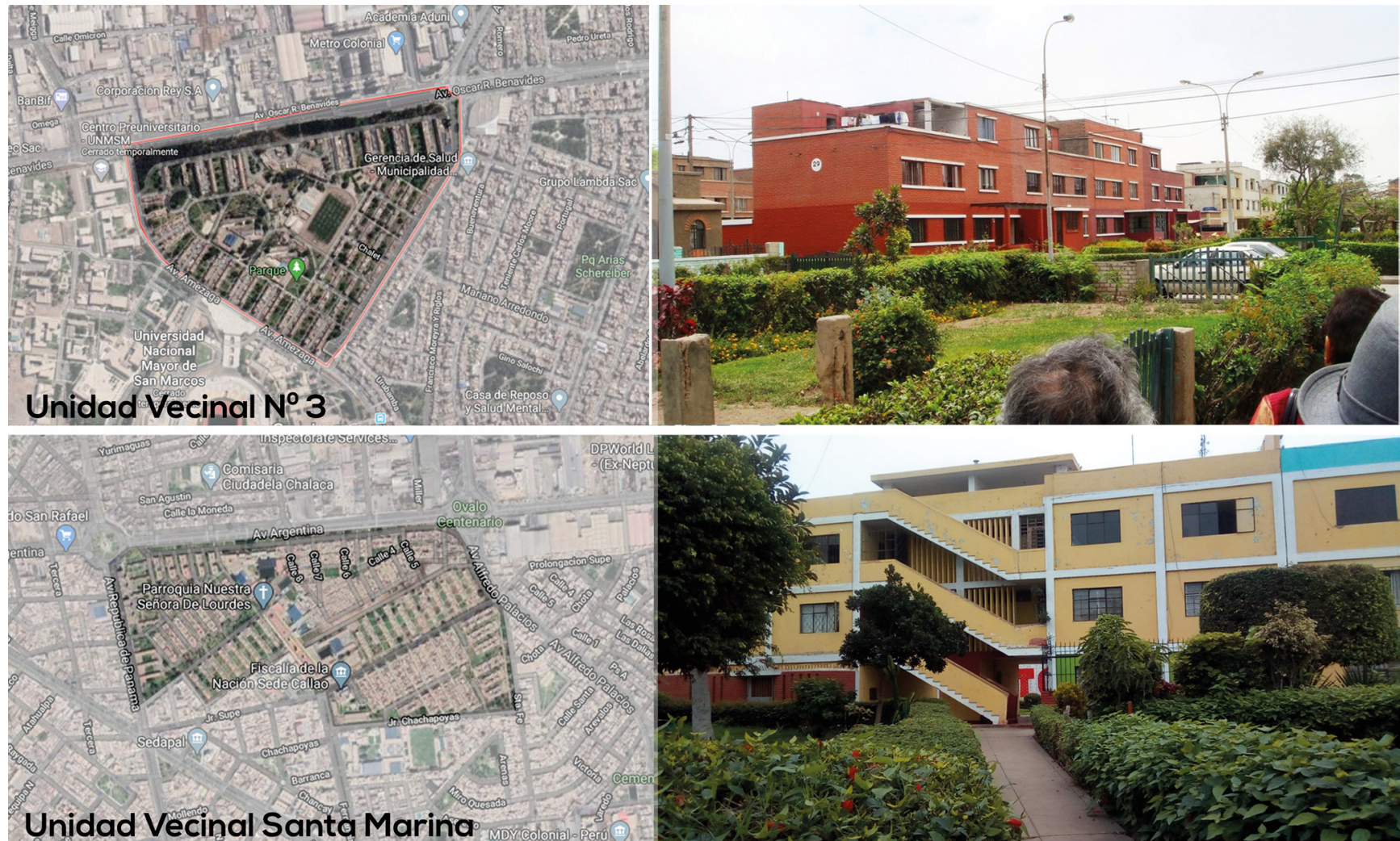

\section{Unidad Vecinal Santa Marina}
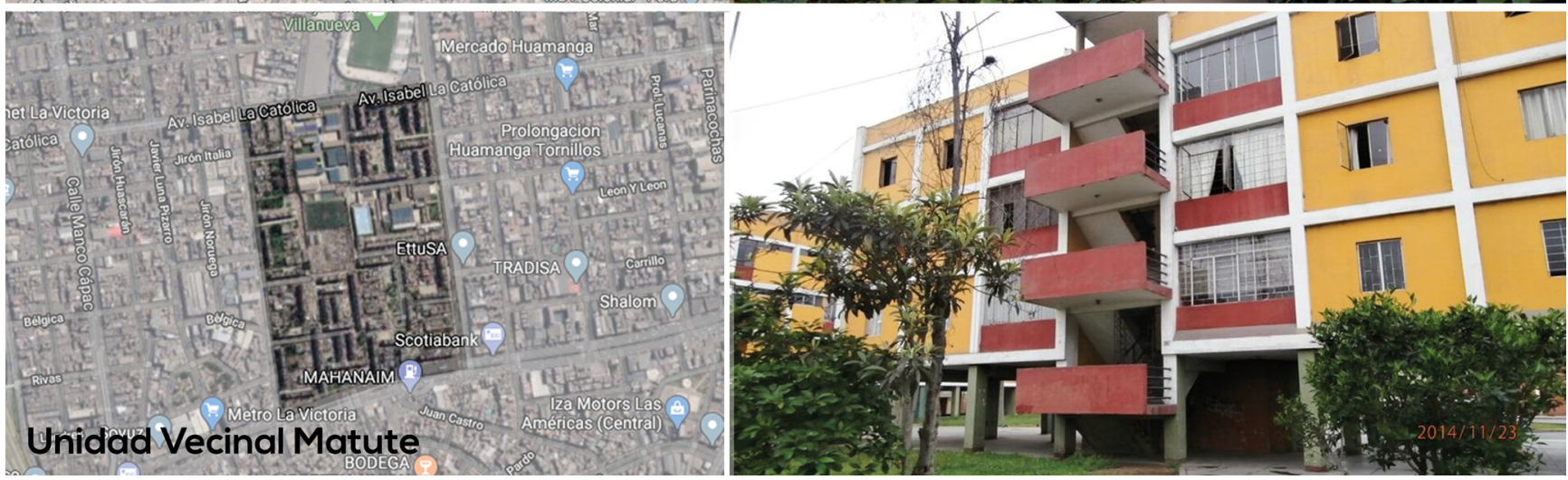

Figura 3. Análisis comparativo: Unidad Vecinal № 3 (arriba), Unidad Vecinal Santa Marina (centro), Unidad Vecinal Matute (abajo). Elaboración propia sobre la base de Google Maps (2020), fotografías obtenidas de http://limamilenaria.blogspot.com/; https://www.adondevivir.com/; registro fotográfico del autor.

El presente estudio es sobre la Unidad Vecinal Santa Marina, desarrollada a mediados del siglo XX (al igual que la UV3 y Matute), contemplada dentro del Plan de Vivienda de 1945, donde participaron los arquitectos de la Comisión Nacional de Vivienda, entre ellos Mario Bianco (arquitecto italiano, quien tuvo una participación importante para el desarrollo de la arquitectura y urbanismo del Perú en la segunda mitad del siglo XX (Montestruque y Fabbri, 2017) y los reconocidos arquitectos de la Agrupación Espacio, Adolfo Córdova y Carlos Williams.

La Unidad Vecinal Santa Marina presenta similitudes en sus virtudes urbanas y arquitectónicas con la UV3 y la Unidad Vecinal de Matute por ser parte del mismo plan y proyectado por arquitectos del mismo equipo, sin embargo, tiene particularidades debido al contexto geográfico y político en el que se desarrolló. 
devenir Vol. 7, N¹4, JULIO - DICIEMBRE 2020, PP. 11-34 - EstudIOS I ISSN 2312-7562 | E-ISSN 2616-4949

UNIVERSIDAD NACIONAL DE INGEEIERÍA, LIMA

doi: https://doi.org/10.21754/devenir.v7i14.761

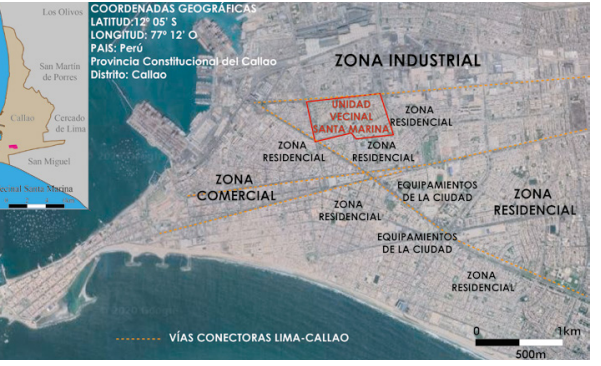

Figura 4. Ubicación de la Unidad Vecinal Santa Marina. Elaboración propia en base a Google Maps (2019) y archivo fotográfico de la autora (2019).

Encuestados por diferencia de edad y años de residencia en U.V. Santa Marina

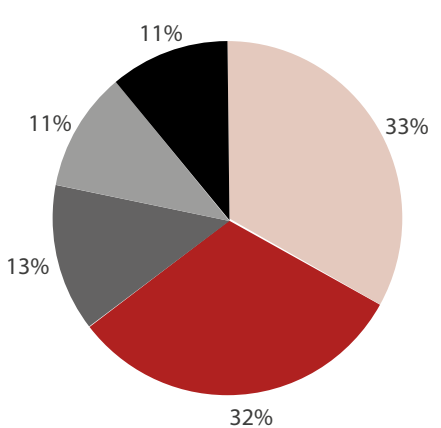

0 Vive aquí desde que nació

1-13 Vive aquí desde su infancia

14-24 Vive aquí desde su juventud

25-64 Vive aquí desde su adultez

No expresaron su tiempo de residencia

Figura 5. Gráfico porcentual de encuestados según diferencia en años entre edad y residencia en U.V. Santa Marina. Elaboración propia sobre la base de datos de encuesta, 2019.
Si bien el diseño de Unidad Vecinal Santa Marina estuvo a cargo de la Comisión Nacional de Vivienda, fue llevada a cabo por la Junta de Obras Públicas del Callao al tomar el mando de gobierno el presidente Manuel Odría en 1948. Es entonces que Santa Marina se contempla dentro del Plan Regulador del Callao, y es el proyecto con mayor extensión y cantidad de viviendas (33 hectáreas para 1709 viviendas) en comparación con las 2 unidades vecinales mencionadas (30 hectáreas para 1172 viviendas, en la UV3 y 17 hectáreas para 900, en Matute). A pesar de que comparte con la Uv3 y Matute, una ubicación estratégica en una avenida que conecte el puerto con el centro de Lima, mientras las otras 2 unidades se ubican hacia el centro de Lima, la cercanía de la Unidad Vecinal Santa Marina al mismo puerto es su característica más atractiva, pues le permite tener una vista al panorama marítimo desde sus niveles más altos.

La Unidad Vecinal Santa Marina, se desarrolla dentro del Plan Regulador del Callao (1950) el cual contenía en la propuesta nuevos centros industriales y proyectos de vivienda cercanos a ellos, de los cuales Santa Marina era su proyecto de mayor expansión y alcance (Plan Regulador del Callao, 1950).

La Junta de Obras Públicas como medida primordial tuvo que iniciar y culminar satisfactoriamente para el Estado las gestiones que permitieron la adquisición de 155,843.41 metros cuadrados de terreno de propiedad de la Compañía Urbanizadora "Santa Marina", a un costo de S/. 2'179,566.90. (Memorias de la Junta de Obras Públicas del Callao, 1953).

\section{Santa Marina en el Callao}

La Unidad Vecinal Santa Marina se encuentra ubicada en el Perú, en el distrito del Callao de la provincia constitucional del Callao. Con coordenadas $12^{\circ} 3^{\prime} 15.91$ "S y $77^{\circ}$ 7'38.35"O. Se conecta al resto de la provincia por los ejes viales de Av. Argentina (al norte), Av. Alfredo Palacios (al este), a la Av. República de Panamá (al oeste) y Jr. Chachapoyas (al sur).

Su ubicación es estratégica pues se encuentra en el eje de la Av. Argentina, conectando el puerto del Callao con las zonas industriales que comenzaron a aparecer en la década de 1940 hacia el Centro de Lima (ver Figura 4).

El terreno donde se desarrolla el conjunto, abarca una superficie territorial de 33.88 hectáreas, y un perímetro lineal de 2.78 kilómetros (Datos obtenidos de Google Earth).

\section{Los resultados}

\section{Santa Marina para su población}

En este apartado las fuentes de información serán los sujetos patrimoniales, cuyas estimaciones se harán mediante encuestas, entrevistas semiestructuradas, sesiones en grupos de enfoque y fichas.

\section{Santa Marina para los residentes y vecinos}

Se analizaron las estimaciones de los residentes y vecinos a través de la encuesta, cuyas respuestas fueron registradas en la ficha de análisis para identificar los tipos de valor patrimonial que estiman.

En cuanto al detalle de los encuestados, según los datos de edad y años de residencia, se observa que el mayor porcentaje vive en la unidad desde su nacimiento (33\%) o desde su infancia (32\%) (ver Figura 5). Afirmando que el grueso de su población encuestada ha sido parte de la historia, el crecimiento y los cambios en el lugar.

Se organizaron las respuestas por procedencia del encuestado: Santa Marina Norte, Santa Marina Sur (comprende zona Centenario) y vecinos cercanos para comparar los 
Tabla 6. Propuesta de escala numérica del nivel de reconocimiento del valor patrimonial según porcentajes

\begin{tabular}{ccl}
\hline $\begin{array}{c}\text { Porcentaje de estimaciones } \\
\text { de valor del total } \\
\text { de participantes }\end{array}$ & $\begin{array}{c}\text { Escala } \\
\text { propuesta }\end{array}$ & Descripcion \\
\hline $0-20 \%$ & 1 & Reconocimiento casi inexistente por su población \\
$20-40 \%$ & 2 & Reconocimiento bajo por su población \\
$40-60 \%$ & 3 & Reconocimiento variable por su población \\
$60-80 \%$ & 4 & Reconocimiento fuerte por su población \\
$80-100 \%$ & 5 & Reconocimiento total por su población \\
\hline Elaboración propia, 2020 & & \\
\hline
\end{tabular}

Tabla 7. Ficha de análisis de valores patrimoniales sobre la base de las respuestas de los residentes de la Unidad Vecinal Santa Marina

\begin{tabular}{|c|c|c|c|c|}
\hline \multirow{2}{*}{\begin{tabular}{l}
\multicolumn{1}{c}{ Edad } \\
Años en la \\
U.V. \\
Zona
\end{tabular}} & \multirow{2}{*}{$\begin{array}{l}65+ \\
59 \\
\text { Sur }\end{array}$} & \multicolumn{3}{|c|}{ Tema y pregunta } \\
\hline & & $\begin{array}{l}\text { Importancia de recono- } \\
\text { cimiento de valor: ¿Qué } \\
\text { es lo más característico } \\
\text { que tiene Santa Marina? } \\
\text { ¿Con qué lo identificas? }\end{array}$ & $\begin{array}{l}\text { Dinámicas de uso: ¿Cuáles } \\
\text { son las distintas activi- } \\
\text { dades que observas que } \\
\text { se pueden realizar en el } \\
\text { barrio de Santa Marina? }\end{array}$ & $\begin{array}{l}\text { Importancia personal } \\
\text { como objeto de valor: } \\
\text { ¿Qué hace Santa Marina } \\
\text { importante para ti? ¿Qué } \\
\text { no cambiarías? }\end{array}$ \\
\hline Respuesta & & $\begin{array}{l}\text { "El ambiente, los jardines } \\
\text { que le da vida" }\end{array}$ & $\begin{array}{l}\text { "Pasear al perrito, paseo, } \\
\text { salgo a tomar aire". }\end{array}$ & $\begin{array}{l}\text { "Desde que me he mu- } \\
\text { dado acá me llegó a acos- } \\
\text { tumbrar tanto. Mi madre } \\
\text { hizo este jardín y lo cuido } \\
\text { hasta ahora. Mi madre } \\
\text { dijo si yo me muero cuida } \\
\text { mi jardín (...)". }\end{array}$ \\
\hline \multicolumn{2}{|c|}{ Casos o factores } & $\begin{array}{l}\text { Extensas áreas verdes y } \\
\text { jardines }\end{array}$ & $\begin{array}{l}\text { Actividades de recrea- } \\
\text { ción }\end{array}$ & $\begin{array}{l}\text { Recuerdos y vínculos } \\
\text { personales significativos }\end{array}$ \\
\hline \multicolumn{2}{|c|}{ Valor(es) Formal(es) } & Estético & & \\
\hline \multicolumn{2}{|c|}{ Valor(es) de Uso } & & Uso & \\
\hline \multicolumn{2}{|c|}{$\begin{array}{l}\text { Valor(es) Simbó- } \\
\text { lico(s) }\end{array}$} & & & $\begin{array}{l}\text { Antigüedad } \\
\text { Conmemorativo } \\
\text { Asociativo }\end{array}$ \\
\hline \multicolumn{2}{|c|}{ Grado de Satisf. } & 5 (Alta) & & \\
\hline
\end{tabular}

resultados. Se contabilizaron las respuestas de cada grupo por tipo de valor patrimonial y se le atribuyó un grado de reconocimiento según la escala propuesta a base de porcentajes (ver Tabla 6).

Para el análisis de la ficha, se realizó mediante la interpretación de respuestas, atribuyéndosele un valor patrimonial según las estimaciones positivas identificadas por cada participante, según las categorías de Valor formal, Valor de uso y Valor simbólico. En la Tabla 07 se presenta como ejemplo una ficha completa de un residente longevo de Santa Marina Sur. En este ejemplo, se identifica el valor formal estético por su respuesta acerca de los jardines como el elemento más característico: en este caso, el participante refiere una estimación positiva a las áreas verdes no por el uso que le da sino por su "ambiente" siendo interpretado como un elemento de armonía y belleza que caracteriza la Unidad. Siguiendo el 
devenir Vol. 7, N¹4, JULIO - DICIEMBRE 2020, PP. 11-34 - EstudIOS I ISSN 2312-7562 | E-ISSN 2616-4949 UNIVERSIDAD NACIONAL DE INGEEIERÍA, LIMA

doi: https://doi.org/10.21754/devenir.v7i14.761

\begin{tabular}{|c|c|c|c|c|c|c|c|}
\hline & & \multicolumn{2}{|c|}{ Santa Marina Norte } & \multicolumn{2}{|c|}{ Santa Marina Sur } & \multicolumn{2}{|c|}{ Vecinos Cercanos } \\
\hline \multicolumn{2}{|c|}{ Valores patrimoniales } & $\%$ de & Escala & $\%$ de & Escala & $\%$ de & Escala \\
\hline \multirow[t]{2}{*}{ Formal } & Artístico & $27 \%$ & 2 & $21 \%$ & 2 & $21 \%$ & 2 \\
\hline & Estético & $34 \%$ & 3 & $29 \%$ & 2 & $41 \%$ & 3 \\
\hline \multirow[t]{5}{*}{ De uso } & Uso & $68 \%$ & 5 & $42 \%$ & 3 & $56 \%$ & 2 \\
\hline & Educativo & $5 \%$ & 1 & $3 \%$ & 1 & $15 \%$ & 1 \\
\hline & Sentimental o personal & $18 \%$ & 2 & $29 \%$ & 2 & $23 \%$ & 2 \\
\hline & Social & $23 \%$ & 2 & $16 \%$ & 1 & $5 \%$ & 1 \\
\hline & Económico & $5 \%$ & 1 & $11 \%$ & 1 & $36 \%$ & 2 \\
\hline \multirow[t]{4}{*}{ Simbólico } & Histórico & $0 \%$ & 0 & $5 \%$ & 1 & $0 \%$ & 0 \\
\hline & Antigüedad & $7 \%$ & 1 & $5 \%$ & 1 & $0 \%$ & 0 \\
\hline & Asociativo & $23 \%$ & 2 & $42 \%$ & 3 & $5 \%$ & 1 \\
\hline & Conmemorativo & $20 \%$ & 2 & $18 \%$ & 1 & $8 \%$ & 1 \\
\hline
\end{tabular}

Gráfico de valores patrimoniales identificados

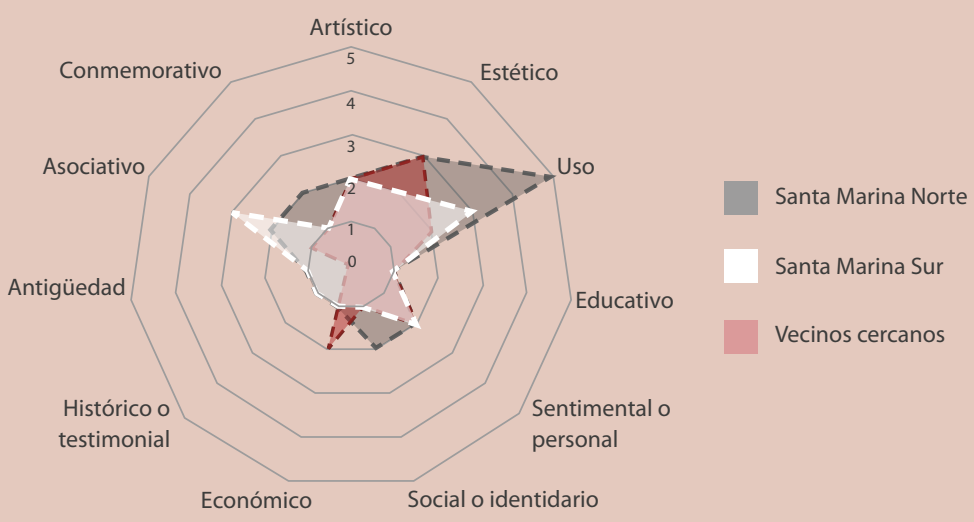

* No se incluye en la tabla los valores patrimoniales de novedad, originalidad, conjunto e investigación porque no se identificó ninguna estimación correspondiente a esas categorías.

Elaboración propia, 2020

ejemplo, el valor de uso es identificado, dado que el participante menciona usos que realiza él mismo además de su residencia y actividades de recreación en sus áreas públicas.

La pregunta sobre la importancia personal de Santa Marina refleja en la respuesta del participante diferentes valores patrimoniales del grupo simbólico: "desde que me he mudado acá, me llegué a acostumbrar tanto" está expresando nostalgia por antigüedad, "Mi madre hizo este jardín y yo lo cuido hasta ahora. Mi madre dijo, si yo muero cuida mi jardín. Esta es la casa que mi padre me compró" expresa la asociación de su vivienda con sus padres (valor asociativo), y con recuerdos específicos que son significativos para el residente (valor conmemorativo).

Este mismo procedimiento se llevó a cabo con las demás respuestas. La Tabla 8 muestra los resultados por tipo de valor patrimonial identificado y la escala atribuida al gra- 


\begin{tabular}{|c|c|c|}
\hline & $\begin{array}{l}\text { Valores } \\
\text { patrimoniales }\end{array}$ & Casos o factores que causan la estimación \\
\hline \multirow[t]{8}{*}{ Formal } & Artístico & $\begin{array}{l}\text { Conformación urbana: Ubicación céntrica respecto a vías principales y centros de trabajo, zonificación } \\
\text { de equipamientos estratégica. }\end{array}$ \\
\hline & & Calidad de su infraestructura arquitectónica: Viviendas con un correcto asoleamiento y ventilación \\
\hline & Estético & $\begin{array}{l}\text { Extensas áreas verdes y jardines, les produce belleza y armonía. Caracteriza la unidad con un fuerte } \\
\text { color verde. }\end{array}$ \\
\hline & & Ambiente tranquilo y cómodo, ausencia de ruido exterior. Genera armonía visual \\
\hline & & Bloques de vivienda singulares, les resulta agradable \\
\hline & Novedad & No identifica \\
\hline & Originalidad & No identifica \\
\hline & Conjunto o indivisibilidad & No identifica \\
\hline \multirow[t]{7}{*}{ De uso } & Uso & Uso residencial y otros diversos usos compatibles (recreación, educación, religioso, comercial, etc.) \\
\hline & Investigación & No identifica \\
\hline & Educativo & $\begin{array}{l}\text { Centros de estudio y aprendizaje, como elementos primordiales para el aprendizaje de los niños y } \\
\text { adolescentes del barrio. }\end{array}$ \\
\hline & Sentimental o personal & Lugar de socialización, por ser un lugar que fomente vínculos de amistad entre vecinos. \\
\hline & $\begin{array}{l}\text { Social o } \\
\text { identitario }\end{array}$ & $\begin{array}{l}\text { Reconocimiento y formación de la identidad de su "gente", caracterizados por sus vecinos como gente } \\
\text { con "alegría", "picardía" "criollismo" y de relación familiar. }\end{array}$ \\
\hline & Económico & $\begin{array}{l}\text { Rentabilidad económica, por contar con zonas comerciales y mercados a poca distancia de las } \\
\text { viviendas. }\end{array}$ \\
\hline & & $\begin{array}{l}\text { Oferta laboral. Los diversos usos y equipamientos que tiene la Unidad Vecinal permiten tener una } \\
\text { oferta laboral amplia para sus residentes y vecinos. }\end{array}$ \\
\hline \multirow[t]{5}{*}{ Simbólico } & Histórico o testimonial & Historia de Santa Marina como parte de la historia del Callao. \\
\hline & Antigüedad & Costumbre por tiempo. Vecinos están acostumbrados a vivir allí por los años en la Unidad. \\
\hline & Asociativo & $\begin{array}{l}\text { Vínculos personales, les resulta importante por la asociación con amigos o familiares que viven o } \\
\text { vivían allí. }\end{array}$ \\
\hline & $\begin{array}{l}\text { Conmemorativo o monu- } \\
\text { mental }\end{array}$ & $\begin{array}{l}\text { Recuerdos personales significativos. Momentos que marcaron la infancia y juventud de los vecinos } \\
\text { vuelven la Unidad importante para ellos. }\end{array}$ \\
\hline & & $\begin{array}{l}\text { Tradiciones, costumbres y leyendas que forman parte de la Unidad Vecinal y es compartida por sus } \\
\text { vecinos }\end{array}$ \\
\hline
\end{tabular}

do de reconocimiento según procedencia. Esta tabla va de la mano con la identificación de factores (ver Tabla 9 y Figura 6), que permitió agrupar las temáticas o casos que permiten la estimación de estos valores.

La función de las unidades vecinales es volverse un barrio autosuficiente, esta idea se refuerza cuando el valor de uso es fuertemente reconocido por sus residentes. Es entendible que sea la zona de Santa Marina Norte quienes tengan un reconocimiento total de este valor patrimonial debido a que el boulevard de Santa Marina con los principales usos (educativos, religiosos y comerciales) se encuentra dentro de este sector próximo a sus bloques Z6, Z7, Z8 Y Z9, que es el más beneficioso para sus residentes.

En la zona sur no hay un valor patrimonial que sea reconocido totalmente por su población, los valores identificados son estimados por algunos grupos y pueden ser variables. Este sector resulta el más dañado socialmente comparado con el plano original del proyecto, la zona sur contemplaría un polideportivo, el cual no fue construido (ver Figura 7), y este terreno fue ocupado por viviendas construidas sin 

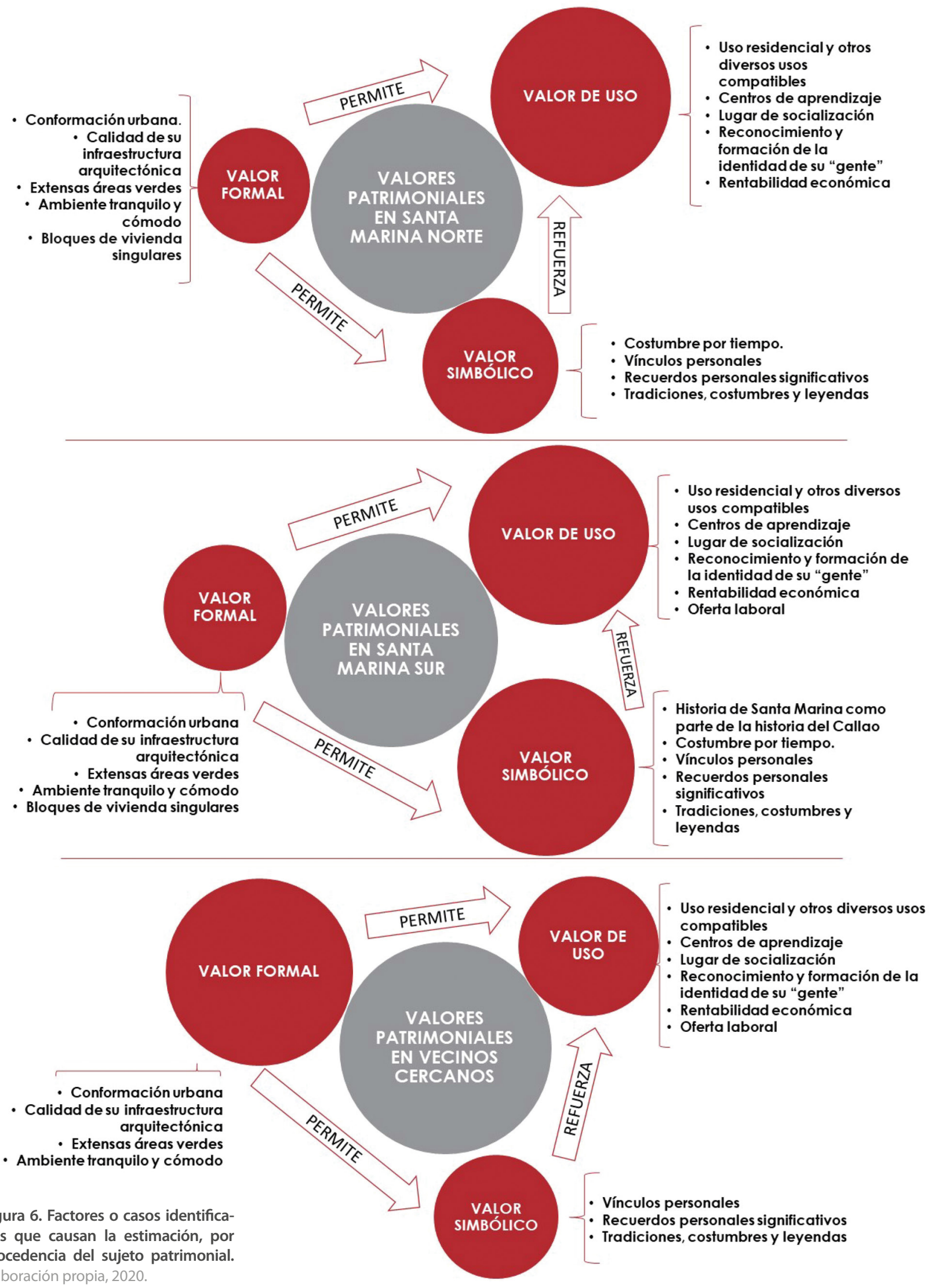

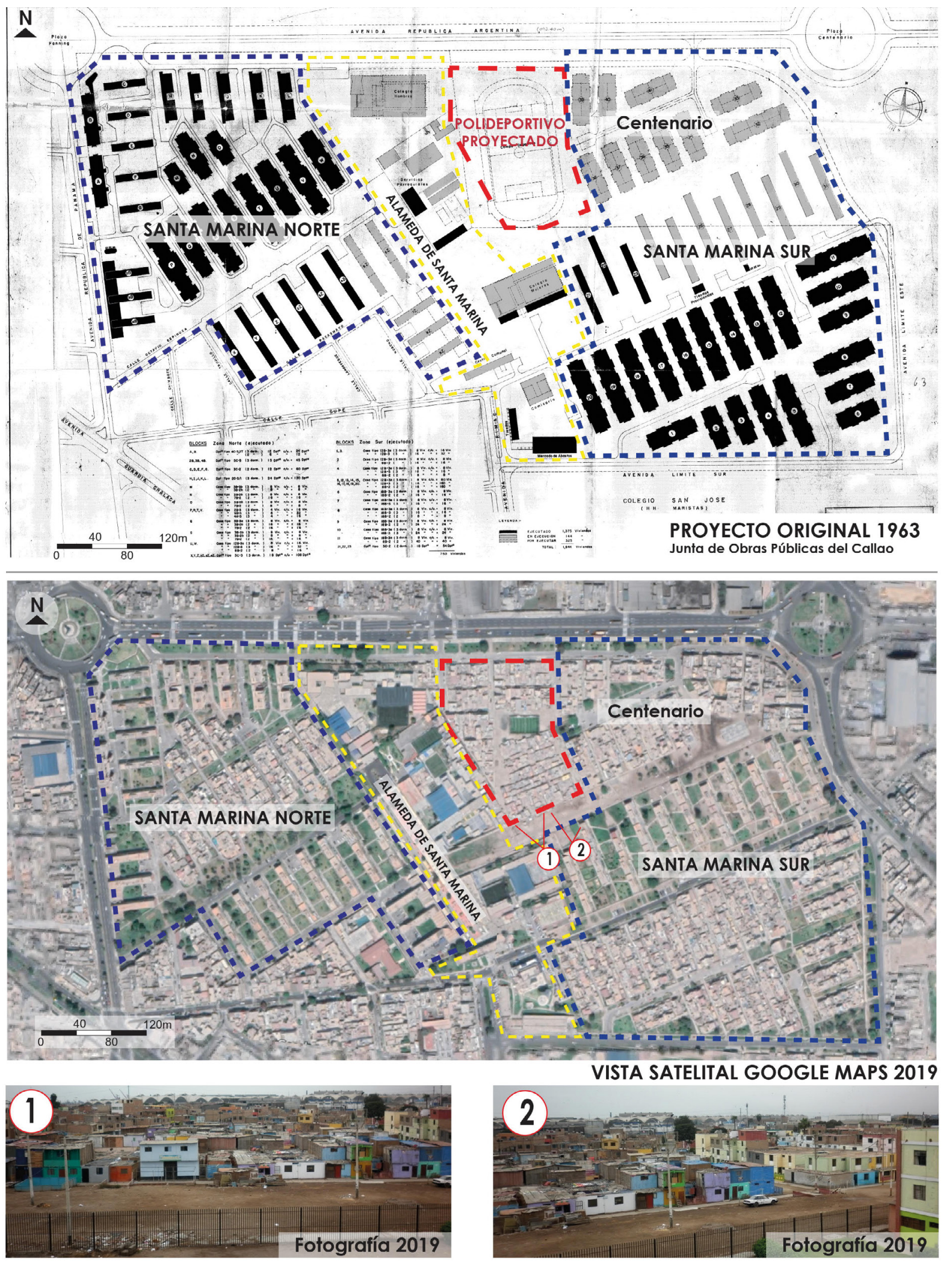

Figura 7. Proyecto original Unidad Vecinal Santa Marina de 1963 (arriba), Vista Satelital de Unidad Vecinal Santa Marina en 2019 y vistas actuales de zona Centenario (abajo. Elaboración propia en base a Junta de Obras Públicas del Callao (1963), Google Maps (2019). Registro fotográfico de la autora (2019). 

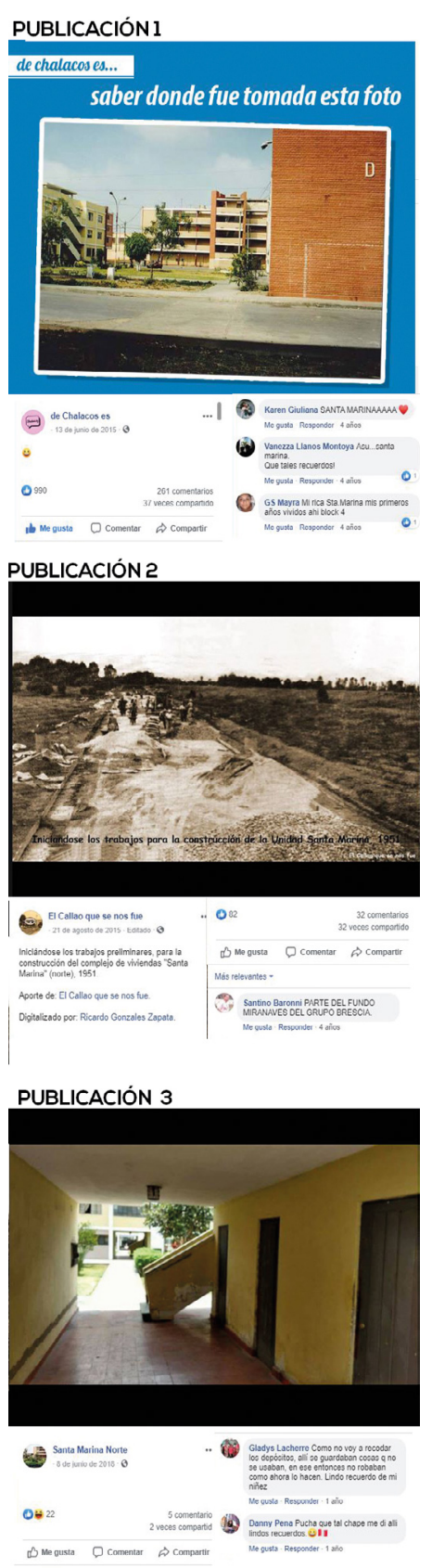

Figura 8. Publicaciones de Facebook referentes a la Unidad Vecinal Santa Marina. Recuperado de página de Facebook de "De Chalacos Es "(Junio, 2015), "El Callao que se nos fue" (Agosto, 2015) y "Santa Marina Norte" (Junio, 2018). mente por sus jardines y áreas verdes) que sus propios residentes. Se puede suponer que esta valoración se da debido a la falta de áreas verdes en sus viviendas, disfrutan de las áreas verdes de Santa Marina cada vez que visitan el barrio.

Otro valor parcialmente reconocible en los vecinos cercanos (y en algunos residentes) es el valor económico. El hecho de que la unidad vecinal tenga múltiples servicios en sus equipamientos permite ser una cuna laboral para sus residentes y vecinos quienes pueden no solo gozar de los servicios, sino también encontrar en ellos una fuente de trabajo.

\section{Santa Marina en las redes sociales}

Estando las redes sociales presentes en la actividad diaria de las personas, muchos residentes, ex-residentes, y vecinos de Santa Marina interactúan en ellas. Desde subir una foto familiar en un parque, un video de la graduación del colegio, fotos de las actividades de los Boy Scouts en Santa Marina, hasta fotos de hace más de 30 años que los vecinos deciden compartir por la nostalgia que les genera.

En la búsqueda, se encontró publicaciones referidas a la Unidad Vecinal Santa Marina que generaban reacciones y comentarios que denotaban sentimientos de nostalgia, reconocimiento y sensaciones positivas hacia el lugar. Se seleccionaron 3 publicaciones con imágenes (ver Figura 8) y se identificó la cantidad de alcance que tuvieron y los tipos de comentarios que generaron (ver Tabla 10).

Previo un análisis rápido de los comentarios, se identificó que muchos de las expresiones positivas hacia la Unidad Vecinal Santa Marina se daban en tiempo pasado o refiriendo situaciones o algún anterior uso atribuido en la unidad. Hecho el conteo, se verificó este supuesto en las publicaciones con imágenes más antiguas (publicación 2 y 3 presenta fotos de 1965 y 1951 respectivamente), donde quienes comentaron, expresaron estimaciones de valor del tipo conmemorativo, asociativo y simbólico demostrando conocer la historia de la construcción del lugar, tradiciones de los vecinos y recuerdos personales. Estas referencias colectivas demuestran una identificación a nivel social de sus vecinos más antiguos (se entiende que son vecinos antiguos por los años que citan en sus comentarios), confirmando que existe un valor social identitario formado por los valores simbólicos que sus comentarios expresan.

En la publicación donde este fenómeno no se evidencia es la de "De Chalacos Es", donde, por el tipo de contenido que se observa en su página web, está dirigido a un público más juvenil con objetivo de difundir la cultura chalaca, mientras que la página "El Callao que se nos fue" sigue la dirección de difundir la historia del Callao mediante fotografía de diversos sucesos significativos del puerto. Por lo tanto, es entendible que los comentarios que denotan más nostalgia sean aquellos realizados por quienes tienen más años en la unidad.

En la publicación de "De Chalacos es" las respuestas son cortas, de reconocimiento e identificación del objeto donde expresan su aprecio llamándolo "mi barrio" y atribuyéndole adjetivos y emoticones que aluden estados de ánimo positivos.

En este caso, se identifica un valor social o identitario que no está respaldado por un recuerdo pasado significativo evidente como en los casos anteriores. Sin embargo, es claro en sus cortas respuestas, y es el caso de mayor alcance entre los 4 ejemplos mostrados.

\section{Santa Marina para los niños}

Para los niños que estudian en los colegios de Santa Marina, su percepción respecto al lugar puede ser distinta de los residentes adultos que han pasado toda una vida allí. Para ellos, su presente resulta más importante debido a su corta edad, por lo tanto, en 
Tabla 10. Análisis de comentarios en publicaciones de Facebook referentes a la Unidad Vecinal Santa Marina

\begin{tabular}{|c|c|c|c|c|}
\hline & & Publicación 1 & Publicación 2 & Publicación 3 \\
\hline \multicolumn{2}{|c|}{ Nombre de la página de Facebook } & De Chalacos Es & El Callao que se nos fue & Santa Marina Norte \\
\hline \multicolumn{2}{|c|}{ Tema documentado en la publicación } & $\begin{array}{l}\text { Fotografía de Bloques de } \\
\text { Santa Marina }\end{array}$ & $\begin{array}{l}\text { Fotografía de la construcción } \\
\text { de Santa Marina en } 1951\end{array}$ & $\begin{array}{l}\text { Fotografía de "Cubos" de } \\
\text { Santa Marina }\end{array}$ \\
\hline \multicolumn{2}{|l|}{ Fecha de publicación } & $6 / 13 / 2015$ & $8 / 21 / 2015$ & $6 / 8 / 2018$ \\
\hline \multicolumn{2}{|l|}{ Fecha de registro } & $5 / 14 / 2020$ & $5 / 14 / 2020$ & $5 / 14 / 2020$ \\
\hline \multicolumn{2}{|l|}{ "Me gusta" } & 990 & 82 & 22 \\
\hline \multicolumn{2}{|c|}{$\begin{array}{l}\text { Comentarios con expresiones positivas hacia } \\
\text { Santa Marina }\end{array}$} & 40 & 13 & 5 \\
\hline \multirow{2}{*}{$\begin{array}{l}\text { Expresiones positivas } \\
\text { (en tiempo pasado) }\end{array}$} & Cantidad & 7 & 10 & 5 \\
\hline & $\begin{array}{l}\text { Ejemplos de comen- } \\
\text { tarios }\end{array}$ & $\begin{array}{l}\text { "La norte! Esta el arco donde } \\
\text { jugábamos mete gol tapa! } \\
\text { XD" } \\
\text { "mis primeros años vividos } \\
\text { ahí block 4" } \\
\text { "santa marina norte chalaco } \\
\text { es sino chapaste en los cubos } \\
\text { no tuviste infancia jajaja" }\end{array}$ & $\begin{array}{l}\text { "Cuantas vivencias en ese } \\
\text { barrio querido, donde lleguè } \\
\text { muy niña a vivir, añoranzas } \\
\text { de un ayer hermoso (...)" } \\
\text { "En el año 1928, el gobier- } \\
\text { no de Augusto B. Leguía le } \\
\text { expropio parte del fundo } \\
\text { Miranaves (...) donde más } \\
\text { tarde se construiria la Unidad } \\
\text { de viviendas Santa Marina". }\end{array}$ & $\begin{array}{l}\text { "Como no voy a recodar los } \\
\text { depósitos (...). Lindo recuer- } \\
\text { do de mi niñez" } \\
\text { "Pucha que tal chape me di } \\
\text { alli lindos recuerdos" } \\
\text { "Allí se jugaba: Puertitas. Que } \\
\text { lindo recuerdo". } \\
\text { "Me era conocido ese lugar } \\
\text { como vivi cerca de la Unidad } \\
\text { Santa Maria Norte tenia } \\
\text { muchas amigas" }\end{array}$ \\
\hline \multirow{2}{*}{$\begin{array}{l}\text { Expresiones positivas } \\
\text { (en tiempo presente o } \\
\text { atemporal) }\end{array}$} & Cantidad & 33 & 3 & 0 \\
\hline & $\begin{array}{l}\text { Ejemplos de comen- } \\
\text { tarios }\end{array}$ & $\begin{array}{l}\text { "Tengo grandes amigos en } \\
\text { Santa Marina...." } \\
\text { "Mi barrio <3 :'(“" } \\
\text { "El rico santa marina peeesss" } \\
\text { "buena Santa marinaa :3" }\end{array}$ & $\begin{array}{l}\text { "Mi barrio querido!!! Los } \\
\text { mejores momentos!!! Lo } \\
\text { Maximo!!" } \\
\text { "Las unidades son para } \\
\text { sacarse el sombrero,cuántos } \\
\text { terremotos y siguen intactas,- } \\
\text { de alquiler-venta a precios } \\
\text { accesibles para el pueblo" }\end{array}$ & / \\
\hline
\end{tabular}

esta investigación se buscó explorar en sus imaginarios de manera lúdica: a través de dibujos libres y dinámicas grupales que fomenten una postura de análisis ante una pregunta que quizá nunca se habían hecho: ¿Por qué me gusta Santa Marina? ¿Qué es lo más importante que tiene?

La muestra que participó de niños de primaria (28 niños) del Colegio Junior Cesar de los Ríos (colegio ubicado en el centro de la alameda de la Unidad Vecinal) demostró respuestas optimistas y una actitud positiva. A pesar de que la mayoría de estos niños no vivían en el barrio, recordaban vívidamente sus actividades allí, por lo que sus respuestas a lo que más les gustaba del barrio se reflejaban en dibujos a color de los espacios públicos (jardines, canchas deportivas) y equipamientos del lugar (ver Figura 9).

A pesar de que se tuvo respuestas refiriendo a la iglesia, la antigua municipalidad o los bloques de vivienda como sus lugares favoritos, el espacio más presente en los imaginarios de los niños de primaria fueron los parques y sitios de recreación como los juegos internos del colegio o el boulevard de Santa Marina donde dibujaban las características bancas de concreto con áreas verdes.

Frases como"Me gusta el parque de Santa Marina" o"Me gusta afuera del colegio, porque me puedo divertir esperando a mis otros primos a que salgan a jugar" refuerzan la idea de que los niños valoran Santa Marina por sus múltiples espacios comunes en donde se llevan a cabo actividades recreativas y/o de nexo social desde espacios inter- 


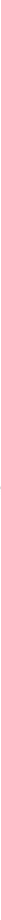

Figura 9. Dibujos de 6 alumnos del $5{ }^{\text {to }} \mathrm{B}$ dibujando su lugar favorito del barrio. Archivo fotográfico de la autora, 2019. nos como los del interior del colegio, a espacios abiertos como las canchas deportivas de la iglesia, el largo boulevard y los amplios jardines entre bloques.

Un fuerte valor de uso en los imaginarios de los niños, que a medida que crezcan puedan convertir estas memorias en un valor simbólico conmemorativo, que, al dejar Santa Marina, cuando vuelvan a ella puedan recordar los momentos alegres que en este lugar experimentaron y les genere una nueva forma de apreciar el barrio a como lo apreciaban de niños.

Con los alumnos de secundaria del Colegio Junior Cesar de los Ríos se realizó otra dinámica grupal que permita generar debate en ellos sobre los diferentes valores que podrían encontrar en la unidad.

A pesar de las limitaciones y el corto tiempo de trabajo, los alumnos lograron identificar elementos y actividades que caracterizan a Santa Marina. En la experiencia, se observó que el grupo con más dificultades fue a quien le correspondía identificar los valores formales. Tras el debate interno, era notorio que, para los alumnos, Santa Marina significaba un lugar de encuentros, de paseos, de actividades en la Iglesia, de actividades deportivas y de actividades educativas, y, por lo tanto, para ellos esto era mucho más importante que la mera forma del edificio.

Aun así, en cuanto al aspecto formal, eran conscientes que los parques y jardines de Santa Marina debido a su color verde y extensión les resultaba lo más llamativo del barrio, y era también los espacios principales donde se desarrollaban las actividades que habían mencionado.

El vínculo sentimental y simbólico que los alumnos tienen hacia Santa Marina está precisamente formado por las amistades que aquí formaron, por los vecinos que saludan día a día, por su relación afectiva con el personal del colegio, con los amigos que viven en el barrio y los recuerdos que vivieron en estos espacios (ver Figura 10).

\section{Santa Marina para especialistas}

Para tener una visión completa sobre el bien como patrimonio se indagó también en los otros dos importantes pilares en la gestión del patrimonio: los profesionales y el gobierno. En cuanto a profesionales se consultó al Arq. Manuel Baca (experto en la rama de patrimonio moderno) el Arq. José Beingolea del Carpio (experto respecto a arquitectura peruana del siglo XX), al Arq. Adolfo Córdova (exponente de la arquitectura moderna en el Perú y proyectista de la Unidad Vecinal Santa Marina) y el Arq. Frank Bonifaz (representante municipal de la Dirección Desconcentrada de Cultura del Callao -DDC). 


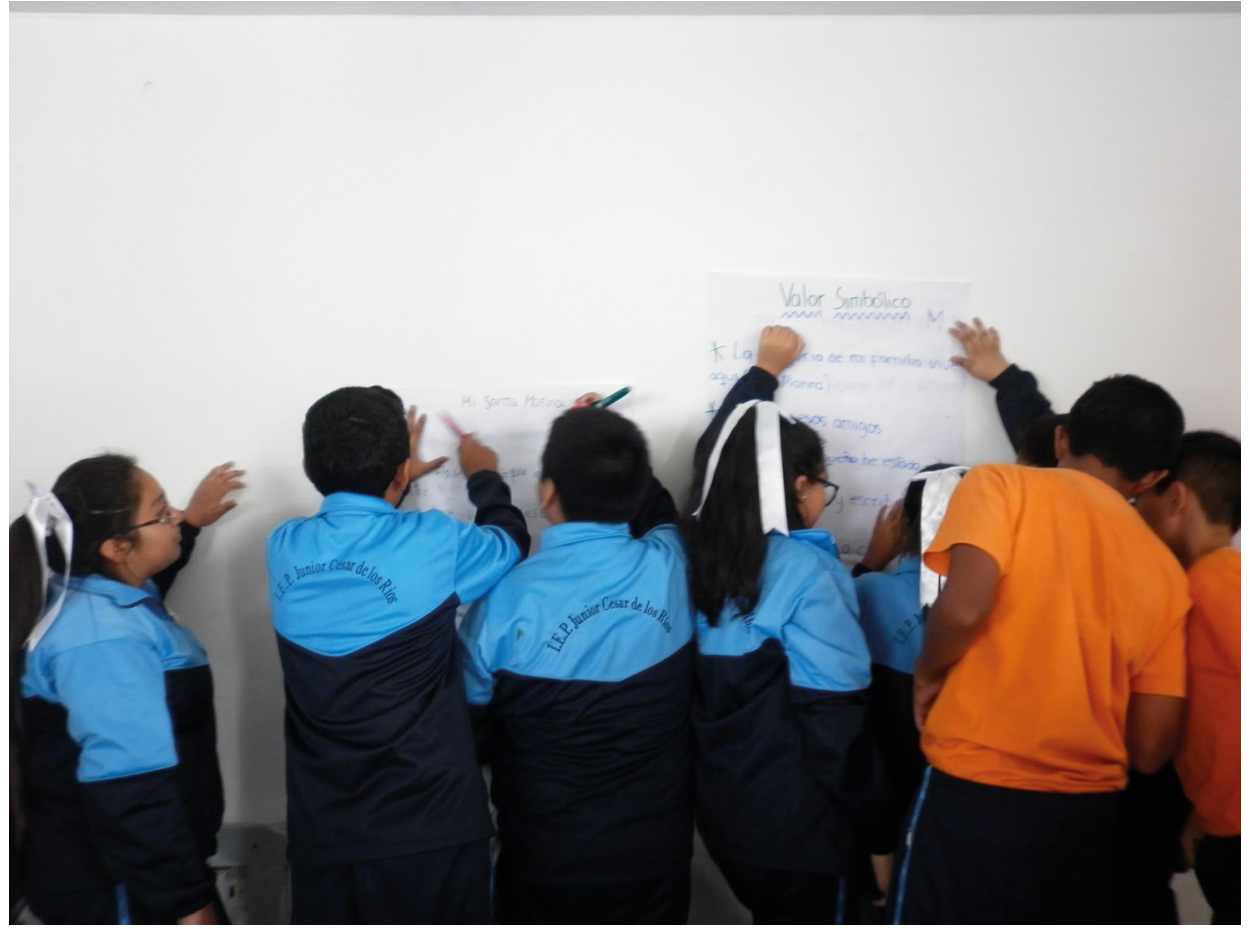

Las estimaciones de valor que ellos encontraron y que en el presente análisis fueron identificados como fuertemente reconocibles fueron las siguientes:

"Son unos de los pocos planes que se han terminado haciendo casi en su totalidad, realidad. Y ahí estaba ubicada lo que sería después la Unidad Vecinal Santa Marina. A favor de eso, jugó el hecho de que en el Callao se creó lo que después sería el gobierno regional. Un ente de gestión pública que planteo unos estudios, básicamente proyectos en lo que participaron los miembros de la agrupación espacio, ahí Miro Quesada, el propio Bianco, Neira, hicieron sendos proyectos. Estaba el teatro del callao, etc., y estaba también la Unidad Vecinal y también ciertos conjuntos de vivienda" (Arq. José Beingolea, comunicación personal, enero del 2019).

"Para Santa Marina fue diferente porque éramos todo un equipo. A Bianco y a mí nos contrataron como arquitectos de vivienda, y llamamos a gente que nos ayudaran (...)

Debe ser un trabajo en conjunto porque el Plan Regulador estaba avanzando también. Seguro había un debate de opiniones entre Miro Quesada con Williams". (Arq. Adolfo Córdova, comunicación personal, febrero del 2019).

"La idea era que los colores se vean, que los volúmenes sean más evidentes, porque el limeño es muy gris, entonces opaca todo. El color es necesario". (Arq. Adolfo Córdova, comunicación personal, febrero del 2019).

"A nivel histórico es un momento importante, otra vez recalco, esta exigencia de los arquitectos modernos en el Perú hizo que finalmente hoy en día estemos hablando de un posible patrimonio moderno" (Arq. Manuel Baca, comunicación personal, febrero del 2019).

"Yo como arquitecto tal vez podría plantear el mejoramiento de las fachadas, los volúmenes del conjunto habitacional o tal vez el mejoramiento interno de los espacios interiores, de los espacios que tengan áreas verdes, de infraestructura saneamiento, que haya una cantidad adecuada de personas viviendo ahí, que en este densificado.". (Arq. Frank Bonifaz, entrevista realizada en mayo del 2019).
Figura 10. Alumnos de $1^{\text {ero }}$ de secundaria realizando la actividad de identificación de valores. Archivo fotográfico de la autora, 2019. 
devenir Vol. 7, N¹4, JULIO - DICIEMBRE 2020, PP. 11-34 - EstudIOS I ISSN 2312-7562 | E-ISSN 2616-4949

UNIVERSIDAD NACIONAL DE INGGENIERÍA, LIMA

doi: https://doi.org/10.21754/devenir.v7i14.761

Propuestas de vecinos

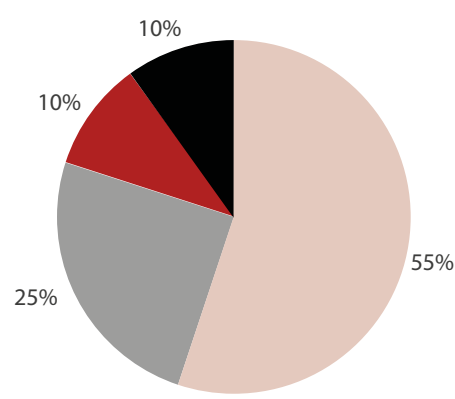

Propuestas para erradicar la delincuencia y mejorar la seguridad de la zona

Aumento de equipamiento y mejora de espacios p]ublicos

Mejora de la calidad de la infraestructura

Propuestas para fomentar el orden y la limpieza de la unidad

Figura 11. Datos porcentuales de los tipos de propuestas para U.V. Santa Marina según sus residentes. Elaboración propia sobre la base de datos de encuesta, 2019.

\section{Grado de satisfacción}

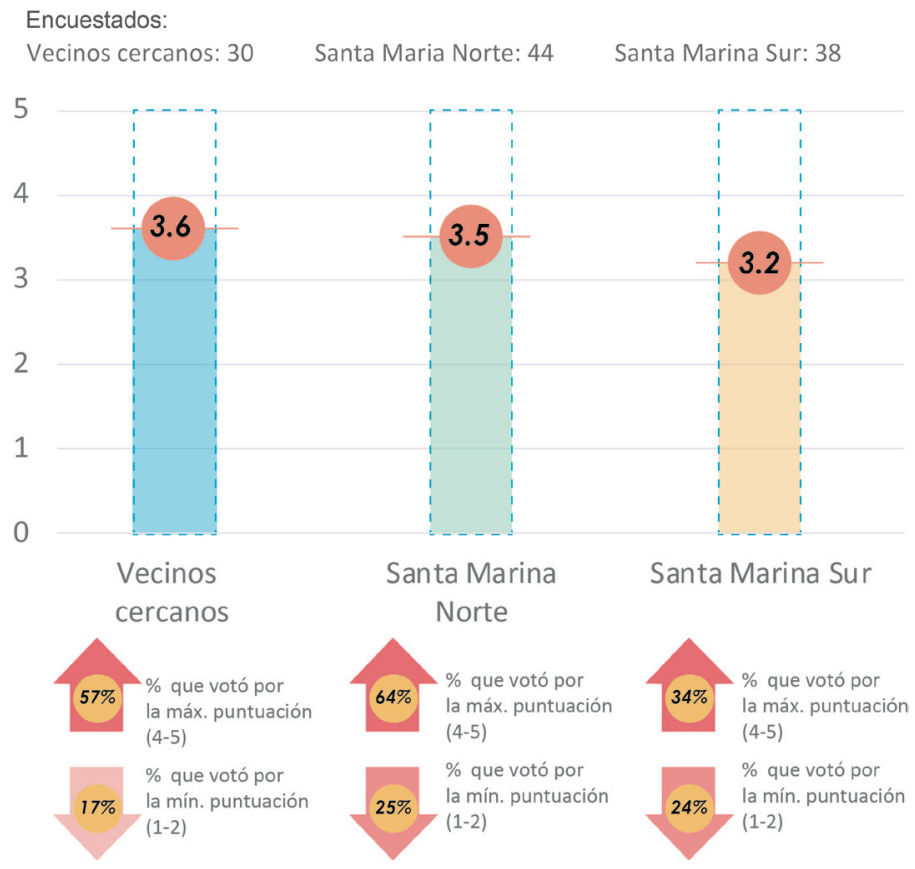

Figura 12. Grado de satisfacción de vivir en Santa Marina según sus residentes y vecinos. Elaboración propia sobre la base de datos de encuesta, 2019

"Yo lo veo casi de la misma tipología respecto a otros conjuntos como la UV3 o la Unidad Vecinal de Mirones". (Arq. Frank Bonifaz, comunicación personal, mayo del 2019).

Los especialistas resaltan de la Unidad Vecinal Santa Marina su valor histórico como proyecto singular de la Arquitectura del Movimiento Moderno y del Callao donde participaron arquitectos representantes de este movimiento. Se puede comprender por sus respuestas el contexto histórico-político en el que fue proyectado y su importancia como hecho histórico y urbanístico.

Sin embargo, tras la entrevista con el representante de la DDC Callao, se dio a notar que hay una intención de proteger edificaciones modernas consideradas patrimonio del siglo XX, pero la prioridad del municipio sigue siendo el Centro Histórico del Callao, el cual se encuentra en un proceso de recuperación. No prioriza por el momento la conservación de edificaciones modernas, y su interés actual en cuanto a la Unidad Vecinal Santa Marina es mínimo, y está netamente enfocado en mejoras físicas de infraestructura.

\section{La delincuencia como amenaza patrimonial}

Adicional a las preguntas de valoración patrimonial, se les consultó a 60 participantes ¿Qué harías para mejorar la Unidad Vecinal Santa Marina?, con el objetivo de identificar los problemas de la unidad desde la mirada de sus residentes y que soluciones plantean (ver Figura 11).

Los resultados demostraron que más del 50\% de ellos consideran la delincuencia su principal problema. Algunos residentes expresaron lo siguiente:

“Pondría más seguridad como por ejemplo policías en la zona a rondar ya que últimamente la delincuencia está cada vez peor y cerca de allí está un barrio que encuentro peligroso como centenario y transitan por ahí cerca al colegio por eso pondría policías a cuidar la zona para evitar robos". (Vecina, 26 años) 
"Cercarlo, poner cámaras y seguridad en todos sus ingresos". (Residente de Santa Marina Norte, 34 años)

“Un centro de estudios gratuito para erradicar la delincuencia y la droga, reordenar centenario". (Residente de Santa Marina Norte, 40 años)

Es claro, según las respuestas, que la delincuencia es el principal problema a trabajar para garantizar una satisfacción cómoda para vivir en el lugar, por lo tanto, es compatible con que ningún sector de Santa Marina llegue a los 4 o 5 puntos de satisfacción al vivir en la unidad (ver Figura 12).

\section{Discusión e interpretación}

Sobre la base de los resultados de los distintos instrumentos utilizados en la investigación, se obtiene que la Unidad Vecinal Santa Marina posee valores patrimoniales diversos, donde, cada grupo actor lo valora manera independiente de acuerdo con su relación con el objeto y el contexto en que expresa su vínculo. Se pone en discusión:

\section{Sobre los sujetos patrimoniales}

- El análisis de la muestra exige experimentar probablemente por primera vez un posicionamiento como actor patrimonial, tanto externo (el nosotros de los otros) e interno (el nosotros de nosotros) correspondiendo los dos aspectos de la dimensión simbólica-identitaria del patrimonio establecida por Santamarina (2005) (como se citó en Nieto, 2018) y permitiendo la comprensión del sujeto respecto al objeto en su dimensión completa.

- El grueso de la muestra, mostró dificultades para responder a las solicitudes del investigador. Puede que, para este caso de estudio, el sujeto haya llevado a la cotidianeidad los beneficios que el objeto le brinda, y por lo tanto ha normalizado sus valores que tiene, descubriéndolos por primera y haciendo conciencia de la necesidad de proteger el bien siendo el primer paso en cuanto a educación patrimonial refiere.

- En la muestra analizada se evidencia que el bajo interés y baja participación ciudadana formada en los últimos años es reflejado en el descuido y alteración de su arquitectura y sistema urbano y en la baja preponderancia de sus valores, reforzando la idea de que la posición de los sujetos respecto al objeto es la principal fuerza que genera cambios en el objeto patrimonial. Por lo tanto, referente al sector de Santa Marina Norte, el cual no se ha visto afectado (en igual magnitud) con la degradación social que la zona sur experimentó, se vuelve el único sector con un reconocimiento casi total de su valor de uso.

- Para una conservación del patrimonio eficiente es necesaria tanto el reconocimiento como el apoyo interrelacionado de los 3 actores; sin embargo, actualmente en U.V. Santa Marina, el nivel de involucramiento de cada actor no es equilibrado y su reconocimiento es ajeno e independiente al de otros actores. Resulta entonces necesario el diálogo y la participación entre los 3 actores si esperamos cambios positivos, como por ejemplo puede darse mediante la difusión del conocimiento de los expertos o de parte de autoridades municipales involucrarse más con las potencialidades que la población encuentra en Santa Marina, etc.

- Actualmente los residentes tienen una débil idea sobre la conservación del patrimonio y lo que implica su compromiso para hacer perdurar Santa Marina en el tiempo. El conocimiento sobre la relevancia histórica de Santa Marina reside solo en sus residentes mas antiguos, siendo evidente en las redes sociales, aún así no se menciona por parte de ellos la relevancia de la edificación como parte del Movimiento Moderno. 
- Se observa que existe una relación entre los valores patrimoniales estimados, donde los valores de uso se llevan a cabo gracias a sus valores formales (la conformación urbana de bloques con amplios espacios públicos y áreas verdes permite actividades de recreación y complementa las actividades de residencia, educativas y de comercio). Además, los valores simbólicos se forman principalmente en base a recuerdos significativos los cuales aluden a los diversos usos atribuidos al bien en tiempo pasado, volviéndose esos usos en los valiosos recuerdos de la actual población.

Respecto a la metodología de investigación activa-participativa:

- Las actividades realizadas de manera directa con los sujetos patrimoniales como entrevistas físicas y sesiones de grupo (colegios) permitió un acercamiento hacia los residentes, pudiendo recoger respuestas más profundas que fueron útiles para la interpretación de resultados. Así también, permitió observar sus conductas frente a las solicitudes del investigador, las cuales reflejaban si su posicionamiento era positivo o negativo respecto al bien patrimonial en cuestión.

- La participación ciudadana es clave para la conservación del patrimonio, por lo cual esta metodología permite recoger las inquietudes e intereses de los actores directos con el bien, la cual, tomada en cuenta en los planes integrales del sector institucional pueden generar cambios y beneficios para este.

- En el caso U.V. Santa Marina, la labor del investigador durante la aplicación de los instrumentos más allá de recopilar información fue, posterior a obtener una respuesta y registrarla, difundir y dar a conocer otros valores patrimoniales identificados por otros actores. En la actividad con los niños, era necesario explicarles de manera concreta que significa valorar el patrimonio, de qué manera se le puede atribuir un valor a un bien y como esto nos afecta. Esta metodología permite dar un paso más donde el investigador puede involucrarse con los investigados y generar cambios a través de la difusión y la educación patrimonial, dando la iniciativa en lo que respecta a conservar el patrimonio en la Unidad Vecinal Santa Marina y generando este interés en sus vecinos.

\section{Conclusiones}

- Comprendiendo que el hecho patrimonial es tanto de la población, los profesionales y los organismos institucionales, es un problema evidente que el valor histórico como arquitectura y urbanismo del Movimiento Moderno claramente identificado por los profesionales no sea identificado por su población.

- De igual manera es necesaria la intervención de la Municipalidad Provincial del Callao, quien se ha mantenido al margen de intervenciones que realcen el valor patrimonial de Santa Marina. Comenzando con intervenir en erradicar la delincuencia como el principal problema que amenaza la conservación patrimonial de la Unidad Vecinal y la satisfacción de vivir en ella.

- Los valores patrimoniales que existen y son percibidos en el bien, están relacionados según la forma en que se desarrollan. En el caso de Santa Marina, los valores formales permiten que exista una diversidad de usos y fomenta la integración social (valores de uso) y a su vez los valores simbólicos se forman como aprecio a las memorias de los usos atribuidos. Esta relación complementaria permite que el bien pueda perdurar en la memoria de sus residentes si es que se sigue conservando sus valores formales.

- Se identifica una diferenciación en la percepción de los valores patrimoniales causados por la sectorización existente en Santa Marina (norte y sur) donde la zona más "peligrosa" de la unidad, la cual se encuentra en el centro y hacia la zona sur se ha vuelto una barrera visual y social entre ambos sectores de la unidad. 
- La diversidad de valores encontrados enriquece la situación de U.V. Santa Marina como patrimonio, sin embargo, solo en la zona norte se identifica un valor fuertemente reconocido mientras que los otros valores identificados tienen una predominancia variable y pueden ir en degradación si no se implementa un plan de conservación para el bien arquitectónico.

- El factor principal que permite la existencia de los valores patrimoniales identificados son los extensos jardines y áreas verdes, volviéndose el elemento primordial a resguardar y conservar de aquí a las próximas generaciones para mantener y fomentar los valores patrimoniales de U.V. Santa Marina

\section{Recomendaciones}

- Es necesario realizar investigaciones sobre la arquitectura del Movimiento Moderno en el Perú, tanto en Lima como en provincias. Sobre todo, en las edificaciones que tienen una gran cantidad de población como las de tipo residencial cuya conservación depende principalmente de sus residentes. Las investigaciones específicas sobre estos bienes resultan indispensables para la difusión y el fomento de los valores patrimoniales y para una apropiación del lugar.

- Se recomienda fomentar, evaluar y poner en marcha un plan de gestión patrimonial por parte de la Municipalidad Provincial del Callao en coordinación con la DDC Callao para que incluya las edificaciones que son legado de la arquitectura del Movimiento Moderno en el Callao, las cuales no son reconocidas como tales por su propia población. Es necesario partir de la identificación de estos bienes patrimoniales en base a sus potencialidades y principales problemas, para luego bajo una metodología del tipo acción-participativa pueda interesar a su población como principales actores, fomentando su apropiación y educación patrimonial para reactivar el sitio.

- Se recomienda fomentar la educación patrimonial en sus residentes haciendo énfasis en los niños desde los colegios, como futuros herederos del patrimonio. No podemos hablar de conservación del patrimonio si los principales interesados no tienen presente de qué manera son afectados o beneficiados. La educación patrimonial debe ser el pilar para encaminar a la población hacia la conservación de sus bienes, y a las nuevas generaciones para protegerlos.

\section{Referencias}

Acevedo, A. y Llona, M. (2016). Catálogo de Arquitectura del Movimiento Moderno. Lima, Perú: Fondo Editorial Universidad de Lima.

Ballart, J. y I Treserras, J. (2001). Gestión del patrimonio cultural. Barcelona, España: Editorial Ariel.

Conti, A. (2015). Patrimonio latinoamericano del siglo XX en la Lista del Patrimonio Mundial. Encuentro de Comités Latinoamericanos de ICOMOS del siglo XX, 1.

De Perú. (s. f.): https://www.deperu.com/educacion/educacion-primaria/escuela-5024-callao-72852

Diaz, F. (2015). La arquitectura del Movimiento Moderno. Revista Anual de Historia del Arte 15 , 221 232. Docomomo. (2014). Docomomo Internacional: https://www.docomomo.com/mission

El Callao. (1950, 9 de Marzo). 2.

Feliu, J. (2014). Propuestas para una epistemología del patrimonio. Devenir, 1(2), 10-26. Lima, Perú.

Gómez, W. (2005). Diseño de un conjunto de viviendas económicas en los Barracones del Callao (Tesis de grado). Lima, Perú: Universidad Nacional de Ingeniería.

Hayakawa, J. (2012). Restauro UNI. Breve antología de textos de restauración del patrimonio monumental edificado. Lima, Perú: Universidad Nacional de Ingeniería.

Hernández, R. (2010). Metodología de la investigación (5 $5^{\text {ta }}$ ed.). México D.F.: McGraw-Hill.

Kahatt, S. (2015). Utopías construidas: Las unidades vecinales de Lima. Lima, Perú: Fondo Editorial PUCP. 
devenir Vol. 7, N¹4, JULIO - DICIEMBRE 2020, PP. 11-34 - EstudIOS I ISSN 2312-7562 | E-ISSN 2616-4949

UNIVERSIDAD NACIONAL DE INGEENIERÍA, LIMA

doi: https://doi.org/10.21754/devenir.v7i14.761

La Unidad Vecinal para el Callao. (1945). El Arquitecto Peruano, 99. Lima, Perú.

Martuccelli, E. (2012). Conversaciones con Adolfo Córdova. Lima: Universidad Nacional de Ingeniería. Amancio Williams: http://www.amanciowilliams.com

Ministerio de Economía y Finanzas. (2018). Portal Web del Sistema de seguimiento de inversiones (SSI): https://ofi5.mef.gob.pe/ssi/Inicio.aspx?tipo=2\&codigo=2352521

Montañez, M. (2016). Gestión y valoración del patrimonio histórico inmueble en el Centro Histórico del Callao. Devenir, 3(6), 98-124.

Montestruque, O. y Fabbri, M. (2017). Mario Bianco: El espacio moderno en el Perú. Lima: Fondo Editorial Universidad de Lima.

Narro, J. (2011). Antecedentes y valoración del Patrimonio Cultural del Perú. Barcelona, España: Universidad Autónoma de Barcelona.

Nieto, C. (2018). La apropiación social como elemento preventivo en la salvaguarda de los bienes culturales. (Tesis doctoral). Valencia, España. Universidad Politécnica de Valencia.

Noelle, L. (2004). Documentación y conservación del movimiento moderno. Docomomo-México. Anales del Instituto de Investigaciones Estéticas, 26(85), 139-141.

Plataforma GLR. (2010, 18 de marzo). La República: https://larepublica.pe/politica/454056-garcia-asistio-a-inauguracion-de-nuevo-palacio-municipal-del-callao/

Portal Web RPP Noticias. (2017, 20 de Junio ). RPP Noticias. Al menos 14 detenidos en un megaoperativo contra el sicariato: https://rpp.pe/lima/policiales-crimenes/al-menos-ocho-detenidos-en-un-megaoperativo-contra-el-sicariato-noticia-1058843

Prensa Chalaca. (2018, 13 de Enero). Página de Facebook Prensa Chalaca. Incendio en Centenario, Callao: https://www.facebook.com/prensachalaca/videos/723469917843901/ $? \mathrm{v}=723469917843901$

Quevedo, G. (14 de octubre de 2016) Portal Web Univisión Noticias. Callao, la ciudad peruana en alerta por la delincuencia: https://www.univision.com/noticias/citylab-delincuencia/callao-la-ciudad-peruana-en-alerta-por-la-delincuencia

Quiroz, F. (2007). Historia del Callao: de Puerto de Lima a Provincia Constitucional. Lima, Perú: Pedagógico San Marcos.

Región Callao. (s.f.): http://copaiefa.regioncallao.gob.pe/iep-junior-cesar-de-los-rios.html

Rivera, L. (1997). Arquitectura y poder. Lima, Perú: Universidad Nacional de Ingeniería.

Ruiz, M. (2003). Unidades vecinales: 40 años de arquitectura urbana moderna en Lima (1945-1985). Lima, Perú: Universidad Nacional de Ingeniería.

Ruiz, M. (2003). Vivienda colectiva estatal en Latinoamérica 1930-1960. Lima, Perú: Universidad Nacional de Ingeniería.

Será una obra de magnificas proporciones el centro cultural que construirá la Junta de Obras Públicas. (09 de Marzo de 1950). El Callao, 2.

Soria, J. y IMP-Corde Callao. (1994). Inventario del Patrimonio Monumental Inmueble del Centro Histórico del Callao. Lima, Perú.

Tarchópulos, D. (2014). La unidad vecinal: objeto de investigación de Josep Lluís Sert. I Congreso Internacional de Vivienda Colectiva Sostenible. 132-137. Barcelona, España: Máster Laboratorio de la Vivienda Sostenible del Siglo XXI.

Un nuevo Callao. (1954). Fanal, IX (41). Lima, Perú: International Petroleum Company, Limited.

Unesco. (2019). World Heritage List - UNESCO: http://whc.unesco.org 